\title{
氮杂环丙烷环加成反应的研究进展
}

\author{
王清宇常宏宏魏文珑刘强 \\ 高文超李彦威* 李 兴* \\ (太原理工大学化学化工学院 生物与制药工程系 太原 030024)
}

摘要 综述了近几年来氮杂环丙烷与含不饱和键化合物环加成反应的研究进展, 主要包括[3+2], [3+3], [3+4], [3+ $2+2],[5+2]$ 和 $[6+3]$ 等环加成反应, 并对其发展方向进行了展望.

关键词 氮杂环丙烷; 环加成; 催化; 不饱和键

\section{Research Progress in the Cycloaddition Reactions of Aziridines}

\author{
Wang, Qingyu Chang, Honghong Wei, Wenlong Liu, Qiang \\ Gao, Wenchao Li, Yanwei* Li, Xing* \\ (College of Chemistry and Chemical Engineering, Taiyuan University of Technology, Taiyuan 030024)
}

\begin{abstract}
The recent progress in the cycloaddition reactions of aziridines is reviewed, mainly including [3+2] and [3+3] cycloaddition reactions. At the same time, several $[3+4],[3+2+2],[5+2]$ and $[6+3]$ cycloaddition reactions are also introduced. Moreover, the prospects of future development are also discussed.

Keywords aziridines; cycloaddition; catalyze; unsaturated bond
\end{abstract}

随着现代有机化学的发展, 杂环类化合物因其具有 一定的反应活性，在有机合成中取得了广泛的应用，其 不仅是构建复杂分子的砌块和重要官能团转化中心, 而 且在不对称合成中也扮演着极其重要的角色, 成为现代 有机合成中最重要的组成部分. 氮杂环丙烷是一类含氮 原子的三元杂环化合物, 其存在于一些有机分子和一些 具有生物活性的天然产物中, 具有抗病毒、抗肿瘤以及 其它生物活性. 由于该三元环的张力极高, 导致其反应 活性较强, 可以与许多化合物发生开环反应用来合成带 有不同官能团的邻氨基类化合物如: 二胺、氨基醇、氨 基酸和生物碱等, 它还可以与其它含有各种不饱和键的 亲偶极体发生环加成反应生成一些新的含氮环状化合 物如: 噁唑烷酮、1,3-噁唑烷、咪唑烷、亚胺和 $\beta$-内酰 胺等具有生物活性的化合物, 其中这些不饱和基团有烯 键、炔基、氰基、羰基、碳氮双键等. 本文将基于含有 不同不饱和键的亲偶极体对近年来氮杂环丙烷参与的 环加成反应研究进展进行综述.

\section{1 氮杂环丙烷[3+2]环加成反应}

\section{1 氮杂环丙烷与含 $\mathrm{C}=\mathrm{C}$ 类化合物的反应}

2008 年, Njardarson 课题组 ${ }^{[1]}$ 报道了用催化剂 $\mathrm{Cu}(\mathrm{hfacac})_{2}$ 催化 $\mathrm{N}$ 上分别带有保护基 $\mathrm{Ts}$ (对甲苯磺酰基) 和 Phth(邻苯二甲酰亚胺)的四类乙烯基氮杂环丙烷进行 的分子内 $[3+2]$ 环加成反应(Scheme 1), 所考察反应得 到的 3-二氢吡咯类产物收率大多能达到 90\%以上，而对 于 Phth 官能团保护的桥环类烯烃氮杂环丙烷比相应的 Ts 保护的氮杂环丙烷反应时得到的产物收率较高, 但是 其产物更易发生重排.

2011 年, 张俊良课题组 ${ }^{[2]}$ 报道了使用路易斯酸 $\mathrm{Y}(\mathrm{OTf})_{3}$ 在温和的条件下催化 $N$-对甲苯磺酰基氮杂环丙 烷通过 $\mathrm{C}-\mathrm{C}$ 键断裂与富电子 3,4-二氢吡喃发生 [3+2] 环加成制备四氢吡咯类衍生物的反应(Scheme 2). 反应 广普性研究表明无论对何种芳香基团取代的 2,2'-二酯 基氮杂环丙烷，反应得到的四氢吡咯类衍生物均能取得

\footnotetext{
*E-mail: lixing@tyut.edu.cn; yanweili59@126.com

Received November 19, 2015; revised December 25, 2015; published online January 15, 2016. Project supported by the Natural Science Foundation of Shanxi Province (No. 2012021007-2). 山西省自然科学基金(No. 2012021007-2)资助项目.
} 


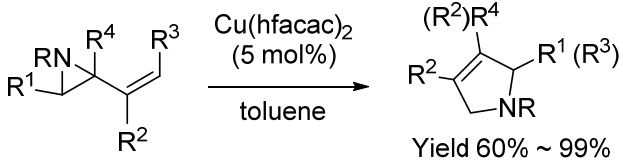<smiles>C=C1CCCCC12CN2[Mg]</smiles>

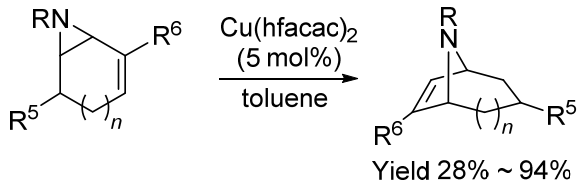<smiles>[R]C=CC12CCCCC1[N+]2=[Sn]</smiles>

$\mathrm{R}=\mathrm{Ts}, \mathrm{Phth} ; \mathrm{R}^{1}=\mathrm{H}, \mathrm{Me}, \mathrm{Ph}$;

$\mathrm{R}^{2}=\mathrm{H}, \mathrm{Me}$, OTBS, $\mathrm{Ph} ; \mathrm{R}^{3}=\mathrm{H}, \mathrm{CO}_{2} \mathrm{Me}, \mathrm{CO}_{2} \mathrm{Et}$;

$\mathrm{R}^{4}=\mathrm{H}, \mathrm{Me} ; \mathrm{R}^{5}=\mathrm{H}, i-\mathrm{Pr}$, OTBS; $\mathrm{R}^{6}=\mathrm{H}, \mathrm{Me}$;

$\mathrm{R}^{7}=\mathrm{H}, \mathrm{CO}_{2} \mathrm{Me} ; n=1,2,3$

图式 $1 \mathrm{Cu}(\mathrm{hfacac})_{2}$ 催化氮杂环丙烷与烯烃的 $[3+2\}$ 环加成反 应

Scheme $1 \mathrm{Cu}(\mathrm{hfacac})_{2}$-catalyzed formal [3+2] cycloadditions of aziridines with alkenes

中等到良好的收率和优秀的非对映选择性. 另外, 对于 非环烯烃，2-甲氧基丙烯与芳基氮杂环丙烷反应得到的 产物具有高的收率和优秀的非对映选择性, 而乙烯基乙 醚和 1-甲氧基-4-乙烯基苯参与反应时分别得到 $80 \%$ 和 $73 \%$ 的收率和中等的非对映选择性.

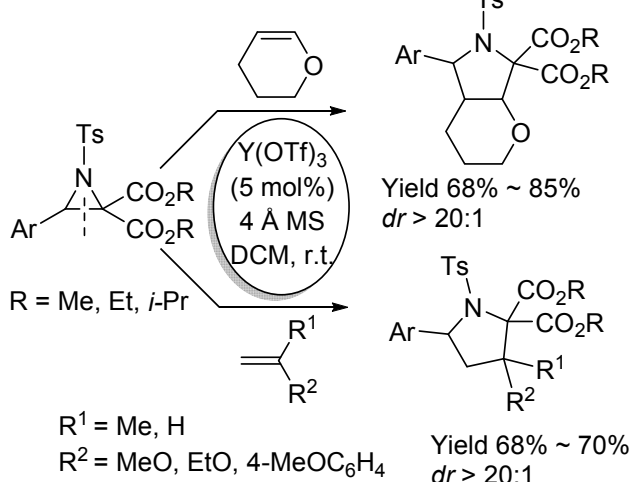

图式 $2 \mathrm{Y}(\mathrm{OTf})_{3}$ 催化氮杂环丙烷与烯烃的 [3+2]环加成反应 Scheme $2 \mathrm{Y}(\mathrm{OTf})_{3}$-catalyzed formal [3+2] cycloadditions of $\mathrm{N}$-tosyl aziridines with alkenes

同年, Aggarwal 课题组 ${ }^{[3]}$ 报道了钯催化下烯基取代 的氮杂环丙烷与 $\alpha, \beta$-不饱和酮的反应(Eq. 1). 该反应使 用 $\left[\mathrm{Pd}(\mathrm{dba})_{3} \cdot \mathrm{CHCl}_{3}\right](\mathrm{dba}=$ trans,trans $-1,5$-二苯基-1,4-戊
二烯-3-酮)作催化剂，磷烷[(三(2-呋喃基)膦、三 (2-甲苯 基)膦或三(4-氟苯基)膦)]作配体，在 $20{ }^{\circ} \mathrm{C}$ 下可顺利进 行，当氮杂环丙烷烯基上连有三甲基硅烷，溶剂为正戊 烷、乙醚或正戊烷/甲基叔丁基醚(Pent/TBME)时，产物 以 3 和 4 为主，收率中等；当烯基连有芳基，溶剂为正戊 烷或 Pent/TBME 时，产物以 5 和 $\mathbf{6}$ 为主，收率中等. 作 者还应用该方法高选择性地合成了红藻氨酸.

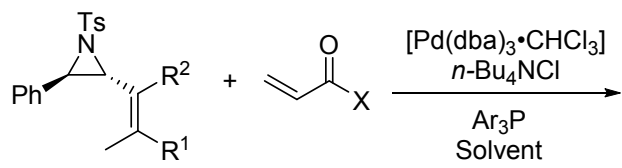

$$
\mathrm{X}=\mathrm{Me}, \mathrm{SEt} \text {; }
$$

$\mathrm{Ar}_{3} \mathrm{P}=(2 \text {-furyl })_{3} \mathrm{P},(2 \text {-tolyl) })_{3} \mathrm{P},\left(4-\mathrm{FC}_{6} \mathrm{H}_{4}\right)_{3} \mathrm{P}$

$\mathrm{R}^{1}=\mathrm{Ph}, 4-\mathrm{ClC}_{6} \mathrm{H}_{4} ; \mathrm{R}^{2}=\mathrm{H}, \mathrm{Me}$;

$\mathrm{R}^{1}=\mathrm{H}, \mathrm{SiMe}_{3} ; \mathrm{R}^{2}=\mathrm{H}$

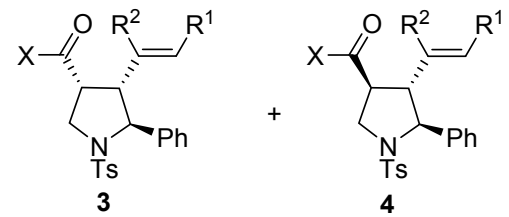

Yield 50\% 66\% $d r(\mathbf{3} / \mathbf{4}):$ 93:7 75:25

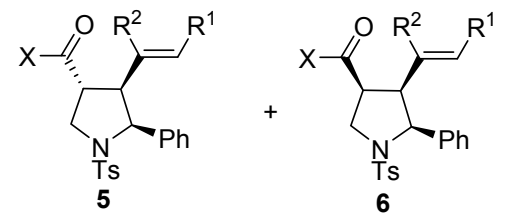

Yield $52 \% \sim 73 \% d r(\mathbf{5} / \mathbf{6}): 94: 6 \sim 20: 80$

2012 年, Shipman 课题组 ${ }^{[4]}$ 报道了 3-甲基乙烯基氮 杂环丙烷在 $\mathrm{BF}_{3} \cdot \mathrm{Et}_{2} \mathrm{O}$ 促进作用下发生分子内环加成反 应来制备顺式-多取代 3-氮杂双环 $[3,3,0]$ 辛烷(Scheme $3)$, 产物收率只有中等. 研究发现 $[3+2]$ 环加成过程是 经过 2-氨酰基阳离子 1 后逐步形成的.

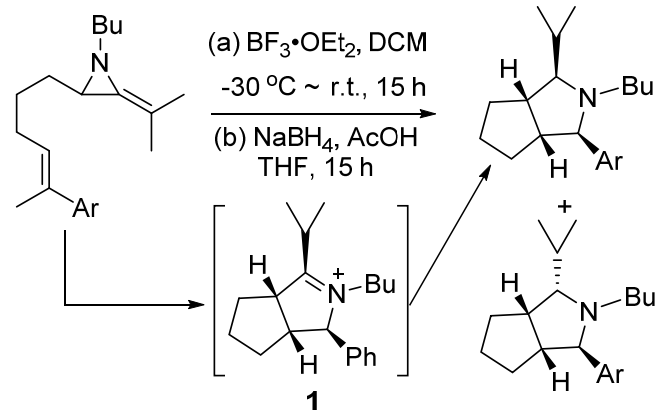

$\mathrm{Ar}=\mathrm{H}, \mathrm{Ph}, 4-\mathrm{MeOC}_{6} \mathrm{H}_{4}, 4-\mathrm{CF}_{3} \mathrm{C}_{6} \mathrm{H}_{4}$ Yield $31 \% \sim 59 \%$

图式 $3 \mathrm{BF}_{3} \cdot \mathrm{OEt}_{2}$ 催化氮杂环丙烷与烯烃的 $[3+2]$ 环加成反应 Scheme $3 \mathrm{BF}_{3} \cdot \mathrm{OEt}_{2}$-catalyzed formal [3+2] cycloadditions of aziridines with alkenes

2013 年, Aggarwal 课题组 ${ }^{[5]}$ 在室温条件下利用 $\mathrm{MgI}_{2}$ 催化 3-甲基乙烯基氮杂环丙烷先发生开环反应，随后再 
与反式丁二酸衍生物反应生成三取代四氢吡咯烷环加 成产物(Scheme 4). 该合成方法简单高效且具有优秀的 对映选择性; 该产物通过两步反应脱保护可形成手性红 藻氨酸, 该物质具有很高的生物活性和药用价值, 被广 泛应用于神经疾病的治疗研究中.

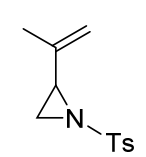<smiles>[X]#CN1C(=O)OC[C@@H]1C</smiles>
$\mathrm{R}^{1}$<smiles>[R]OC(=O)[C@H]1CN([AsH2-])[C@@H](C(C)=O)[C@H]1C([X])=O</smiles>

图式 $4 \mathrm{MgI}_{2}$ 催化氮杂环丙烷与烯烃的[3+2]环加成反应 Scheme $4 \mathrm{MgI}_{2}$-catalyzed formal [3+2] cycloadditions of aziridines with alkenes

2014 年, Shibata 课题组 ${ }^{[6]}$ 使用 $\mathrm{Bu}_{2} \mathrm{SnI}_{2}$ 作为一种有 效的催化剂催化 2-甲烯基氮杂环丙烷与 1,1-二氧基烯烃 发生的 $[3+2]$ 环加成反应(Eq. 2). 研究发现不管是芳基、 萗基还是呋喃基取代的烯烃都能得到三取代环戊烷亚 胺的产物，收率最高可达 $93 \%$.

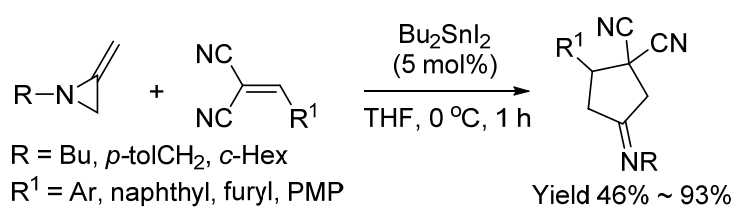

2015 年, Dauban 课题组 ${ }^{[7]}$ 以氮杂环丙烷与亚甲基环 烷烃(1.5 equiv.)作反应原料, 在 $\mathrm{BF}_{3} \cdot \mathrm{Et}_{2} \mathrm{O}$ (1.5 equiv.)作 用下, $\mathrm{DCM}$ 为溶剂, 于 $-78{ }^{\circ} \mathrm{C}$ 下反应得到 1 -氮杂 $[4, n]$ 烷烃产物(Eq. 3). 作者对不同的底物都进行了扩展, 均 取得了中等的收率; 并且将底物范围扩展到氮杂环丁 烷, 反应活性也没有降低. 研究证明 $\mathrm{N}$ 原子上连接的基 团在 $\mathrm{C}-\mathrm{N}$ 键断裂形成 1,3 偶极子的时候起到控速作用, 当连有吸电子基时会限制反应的进行，从而降低反应收 率. 除此之外, 作者还运用 DFT 计算方法更加精确地预 测了此 [3+2] 环加成反应的机理, 发现通过 $\mathrm{C}-\mathrm{N}$ 键断裂形成的 1,3-偶极子是决定反应速率的步骤.

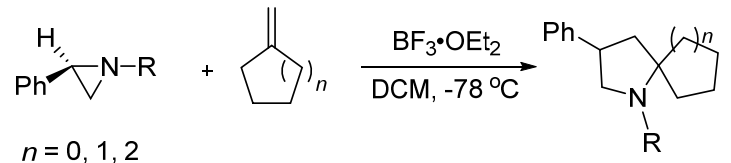

$n=0,1,2$ $\mathrm{R}$ $X=\mathrm{Ph}, 4-\mathrm{MeC}_{6} \mathrm{H}_{4}, 4-\mathrm{MeOC}_{6} \mathrm{H}_{4}, 4-\mathrm{NO}_{2} \mathrm{C}_{6} \mathrm{H}_{4}$
2015 年, 侯雪龙课题组 ${ }^{[8]}$ 完成通过 Pd 催化剂催化 乙烯基氮杂环丙烷与 $\alpha, \beta$-不饱和酮发生非对称 $[3+2]$ 环 加成生成 2,4-双取代四氢吡咯的反应(Eq. 4). 研究发现 在 $\mathrm{KBr}$ 促进的基础上，取代乙烯基酮与乙烯基氮杂环丙 烷在钯催化下发生迈克尔加成/分子内环加成串联反应, 乙烯基酮中 $\mathrm{R}^{2}$ 不管是芳基、杂原子还是脂肪基都适合 作迈克尔受体, 得到的相应四氢吡咯有高的收率、区域 和对映选择性.

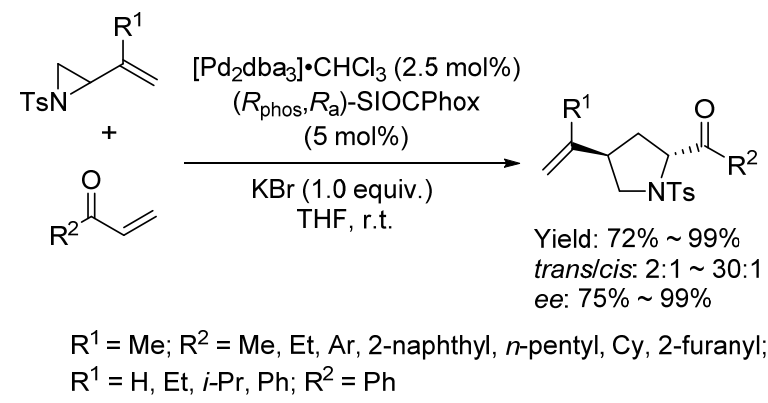

2015 年, 王瑞 课题组 ${ }^{[9]}$ 采用镁试剂在非手性配体 的协助下完成了内消旋氮杂环丙烷与 C3-烷基吲哚发生 $[3+2]$ 环加成制备吲哚并四氢吡咯衍生物的反应(Eq. 5). 在最优条件下，对不同 C3-烷基取代的吲哚进行扩展， 环化产物都得到中等左右的收率以及高的非对映和对 映选择性，C7 被甲基取代的吲哚反应仅得的 19\%的收 率. 而对不同的氮杂进行扩展, 环已烷和环庚烷取代的 氮杂环丙烷可得到优秀的非对映和对映选择性，而环戊 烷氮杂则不能和 C3-烷基吲哚发生反应. 另外芳基取代 的氮杂环丙烷也可得到良好的收率和对映选择性.

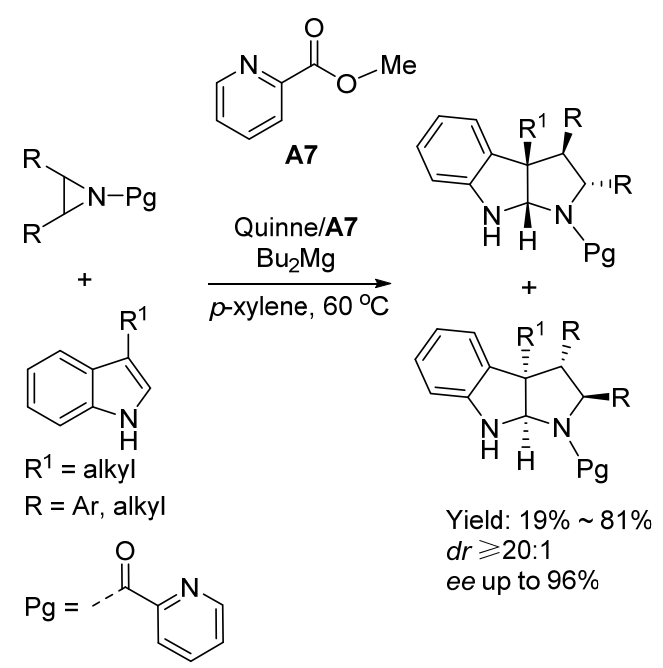

2015 年, 赵刚课题组 ${ }^{[10]}$ 报道了用 $\operatorname{Pd}(\mathrm{II})$ 作催化剂催 化氮杂环丙烷与 C3-烷基取代的吲哚发生 $[3+2]$ 环加成 制备吲哚并吡咯衍生物的反应(Eq. 6). 该反应是在室温 下，甲苯作溶剂，以 $10 \mathrm{~mol} \% \mathrm{Pd}(\mathrm{PhCN})_{2} \mathrm{Cl}_{2}$ 作催化剂， 
不添加任何配体条件下进行的, 对吲哚底物进行扩展发 现吲哚苯环上取代基的位置及电子性质对反应影响较 小, 多数反应都可取得良好的收率和中等到良好的非对 映选择性; 而吲哚 C3 位置连有环己基或异丙基时反应 只取得 36\%或 34\%的收率和中等的非对映选择性. 对氮 杂环丙烷进行扩展表明芳基苯环上取代基的电子性质 对反应没有显著影响, 多数反应都取得了良好的收率和 中等到良好的非对映选择性.

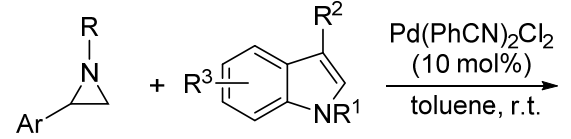

$\mathrm{R}=\mathrm{Ts}, \mathrm{Ns}, 4-\mathrm{MeOC}_{6} \mathrm{H}_{4} \mathrm{SO}_{2}, 4-\mathrm{BrC}_{6} \mathrm{H}_{4} \mathrm{SO}_{2}, \mathrm{Pg}$ $\mathrm{R}^{1}=\mathrm{Me}, \mathrm{Bn} ; \mathrm{R}^{2}=\mathrm{Me}, \mathrm{Cy}, i-\mathrm{Pr},\left(\mathrm{CH}_{2}\right)_{2} \mathrm{OBn}$; $\mathrm{R}^{3}=\mathrm{H}, \mathrm{F}, \mathrm{Br}, \mathrm{MeO}$

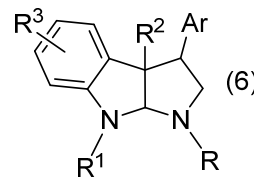

Yield 34\% 91\% dr. 2.5:1 > 20:1

\section{2 氮杂环丙烷与含 $\mathrm{C} \equiv \mathrm{C}$ 化合物的反应}

2005 年, 马大为课题组 ${ }^{[11]}$ 利用非活化的氮杂环丙 烷与 7-碘-2-庚炔乙酯(或其类似物)反应来制备多取代的 2,3,5,6,7,8-六氢吲哚嗪化合物(Scheme 5). 该反应是在 干燥的 $\mathrm{CH}_{3} \mathrm{CN}$ 溶剂中, 于 $\mathrm{K}_{2} \mathrm{CO}_{3}$ 作用下, 经过两个 $\mathrm{S}_{\mathrm{N}} 2 /[3+2]$ 环加成反应得到相应的产物, 对于底物进行 扩展多数反应可以得到良好的收率, 但是当氮杂环丙烷 芳环上连有强富电子基团时反应只得到中等的收率.

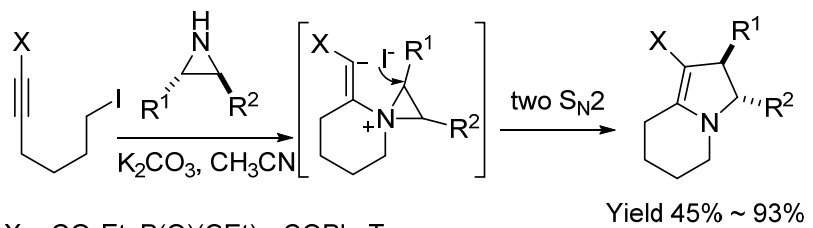

$\mathrm{X}=\mathrm{CO}_{2} \mathrm{Et}, \mathrm{P}(\mathrm{O})(\mathrm{OEt})_{2}, \mathrm{COPh}, \mathrm{Ts}$;

$\mathrm{R}^{1}=\mathrm{Ar} ; \mathrm{R}^{2}=\mathrm{H}, \mathrm{CH}_{2} \mathrm{OBn}$

图式 5 氮杂环丙烷与炔烃的 $[3+2]$ 环加成反应 Scheme $5[3+2]$ cycloadditions of aziridines with alkynes

2009 年, Wende 课题组 ${ }^{[12]}$ 报道了炔作为亲偶极体与 氮杂环丙烷的 $[3+2]$ 环加成反应(Eq. 7). 作者发现使用 $\mathrm{AgSbF}_{6}$ 作催化剂, $\mathrm{DCM}$ 作溶剂, 底物具有一定的普适 性, 不管是芳基内炔烃还是末端炔烃, 反应得到中等到 优秀收率的单一产物, 而脂肪炔仅能得到差到中等的收 率. 对于一系列的芳基氮杂环丙烷, 不管是 NTs 还是 $\mathrm{NNs}$ 保护的氮杂环丙烷反应都得到收率较高的单一产 物; 而 NBoc 保护的氮杂环丙烷在 $\mathrm{AgSbF}_{6}$ 的催化作用下 即使温度达到 $60{ }^{\circ} \mathrm{C}$ 也不发生反应. 作者还发现路易斯 酸 $\mathrm{Sc}(\mathrm{OTf})_{3}$ 和质子酸 $\mathrm{TfOH}$ 也能催化该反应, 得到高区 域选择性的带有不同官能团的 2-二氢吡咯类化合物.

同年, 汪志勇课题组 ${ }^{[13]}$ 报道了用 $\mathrm{FeCl}_{3}$ 作催化剂催 化氮杂环丙烷与芳基炔烃反应生成 2-二氢吡咯化合物

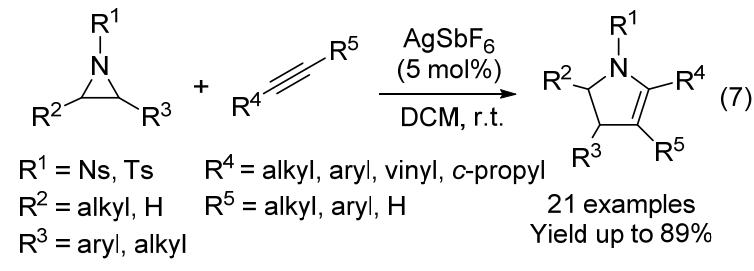

(Eq. 8). 该反应是在 $\mathrm{N}_{2}$ 保护下, 于 $\mathrm{CH}_{3} \mathrm{NO}_{2}$ 溶剂中, $20^{\circ} \mathrm{C}$ 条件下进行. 对芳基炔烃研究发现强供电子基取代 的炔烃有利于反应的进行, 取得高的收率, 弱吸电子基 取代的炔烃对反应有轻微的影响使收率降低, 而强吸电 子基取代的炔烃没有生成相应的产物. 对于各种氮杂, 反应都可取得较好的收率.

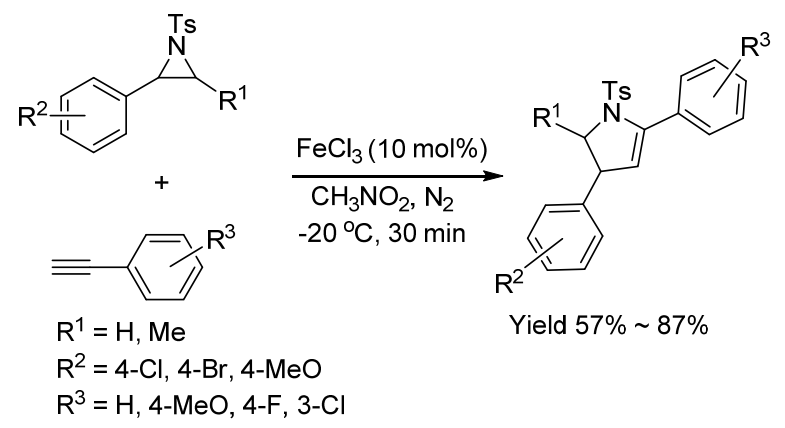

2009 年, 涂永强课题组 ${ }^{[14]}$ 报道了在 $\mathrm{PPh}_{3} \mathrm{AuCl} /$ $\mathrm{AgOTf}$ 催化作用下, 炔丙基氮杂环丙烷经过重排形成三 取代吡咯类化合物的反应(Eq. 9), 该反应涉及到环化/开 环/Wagner-Meerwein 串联反应. 对氮杂进行扩展发现底 物炔基末端的 $\mathrm{R}$ 基不管是吸电子基还是供电子基, 相应 反应都能获得中等到良好的收率; 相似的，当 $R$ 为杂芳 基时，反应也可得到良好到优秀的收率. 对氮杂环丙烷 连有的各种碳环进行考察发现五元环底物比六元环底 物反应快, 这可能是由于形成六元环产物比七元环更容 易; 另外, 对于无环丙炔氮杂环丙烷，在此条件下也能 发生反应，得到产物收率为 $76 \%$.

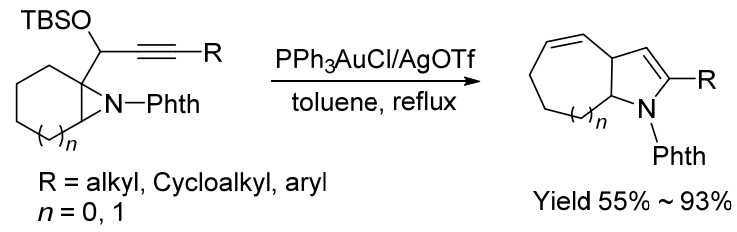

2010 年, Khlebnikov 课题组 ${ }^{[15]}$ 通过加热氮杂环丙烷 形成 1,3 偶极子, 再与非对称的乙炔羧酸酯类化合物发 生环加成反应得到 $c i s-3$-芳基- $3,13 b$-二氢苯并 $[b, f$ 吡咯 $[1,2-d][1,4]$ 氧杂唤庚因羧酸酯 (Scheme 6), 能得到 $73 \% \sim 93 \%$ 的收率. 该产物于室温下在 $\mathrm{MnO}_{2}$ 作用下脱 氢得到相应的吡咯衍生物收率达 $94 \% \sim 99 \%$.

2011 年, 张俊良课题组 ${ }^{[16]}$ 报道了 $\mathrm{Sc}(\mathrm{OTf})_{3}$ 催化的炔 烃与 $N$-对甲苯磺酰基氮杂环丙烷的 $[3+2]$ 环加成反应 


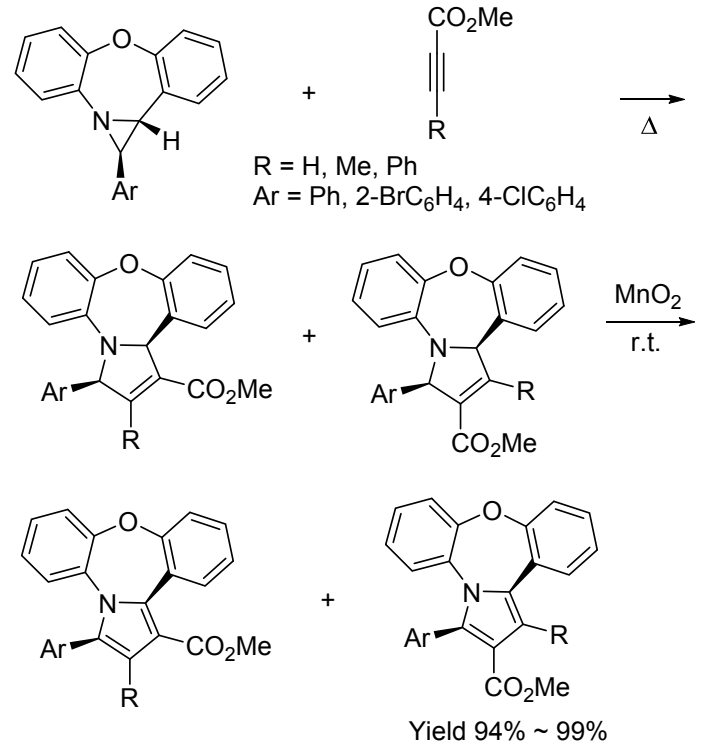

图式 6 氮杂环丙烷与炔烃的 $[3+2]$ 环加成反应

Scheme $6[3+2]$ cycloadditions of aziridines with alkynes

(Eq. 10), 该反应通过氮杂环丙烷 $\mathrm{C}-\mathrm{C}$ 键断裂先形成甲 亚胺叶立德中间过渡态, 随后该过渡态再与炔烃在室温 下发生加成反应得到最终产物. 反应普适性的考察表明 所考察的 22 种底物都得到中等到优秀的收率 $(65 \%$ 91\%).

$$
\begin{aligned}
& \mathrm{R}=\mathrm{Me}, \mathrm{Et}, \mathrm{i}-\mathrm{Pr} ; \mathrm{Ar}^{2}=\mathrm{PMP}, 4-\mathrm{O}_{2} \mathrm{NC}_{6} \mathrm{H}_{4} \\
& \mathrm{R}^{1}=\mathrm{Me}, \mathrm{Br}, \mathrm{Ph}, \mathrm{TMS}, \mathrm{CO}_{2} \mathrm{Me}
\end{aligned}
$$

\section{3 氮杂环丙烷与含 $\mathrm{C}=\mathrm{N}$ 类化合物的反应}

2005 年, Lee 课题组 ${ }^{[17]}$ 报道了用卤化物型路易斯酸 催化手性氮杂环丙烷与异氧酸酯来合成光学纯 $N, N^{\prime}$-双 取代咪唑烷酮(Eq. 11). 该反应是在室温下, $\mathrm{MgBr}_{2}$ 作催 化剂, 二氧六环为溶剂条件下进行. 对异氰酸酯广普性 研究表明, 所考察底物都得到中等到良好的收率, 且富 电子基取代的芳基异氧酸酯作底物时收率更高. 而对于 烷基异氧酸酯, 则使用 $\mathrm{MgBr}_{2} \cdot \mathrm{Et}_{2} \mathrm{O}$ 或三甲基氯硅烷 (TMSCl) 作催化剂, 在 THF 溶剂中反应 $10 \mathrm{~min} \sim 1 \mathrm{~h}$, 可 得到良好收率的产物.

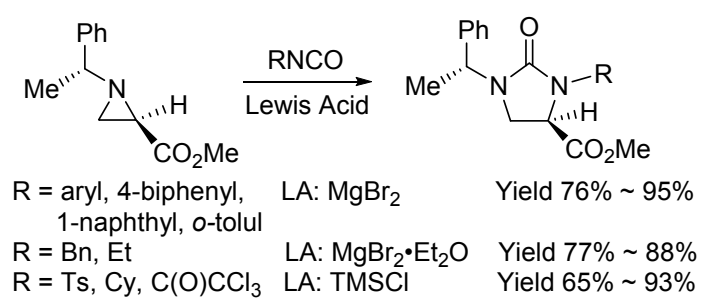

2011 年, 王彦广课题组 ${ }^{[18]}$ 报道了 AgOTf 催化氮杂 环丙烷经 $\mathrm{C}-\mathrm{C}$ 键断裂与亚胺发生 $[3+2]$ 环加成反应生 成咪唑烷衍生物的反应(Eq. 12). 该反应以 1,2-二氯乙烷 (DCE)作溶剂, $4 \AA \mathrm{MS}$ 为添加剂在 $50{ }^{\circ} \mathrm{C}$ 条件下反应, 所考察的 13 种底物均取得了中等到良好的收率, 且产 物以反式为主.

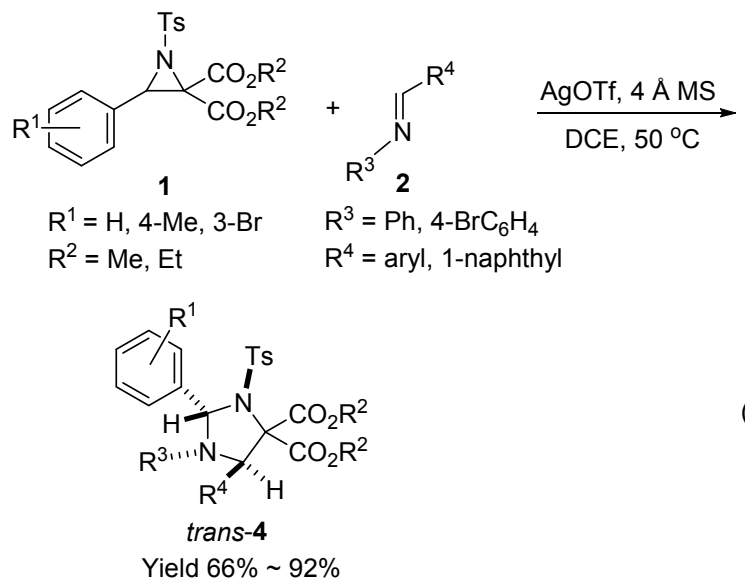

2012 年, 张俊良课题组 ${ }^{[19]}$ 报道了在 $\mathrm{Y}(\mathrm{OTf})_{3}$ 催化作 用下氮杂环丙烷经 $\mathrm{C}-\mathrm{C}$ 键断裂与亚胺发生 $[3+2]$ 环加 成生成多取代四氢咪唑烷的反应(Eq. 13). 该研究使用 苦胺与对氯苯甲醛衍生的醛亚胺与 $N$-对甲苯磺酰基氮 杂环丙烷的反应作模板反应，通过对反应条件优化篮选 得出催化剂 $\mathrm{Y}(\mathrm{OTf})_{3}$ 用量为 $5 \mathrm{~mol} \%, 4 \AA \mathrm{MS}$ 作添加剂, 在 DCE 中于室温条件下, 反应可取得 $85 \%$ 的收率和 $>$ 20:1 的非对映选择性. 对不同的芳香亚胺底物广普性 研究表明, 富电子和缺电子官能团取代的 $N$-茮基亚胺 反应均可得到中等到良好的收率; 值得注意的是, 含有 强富电子官能团的亚胺反应可取得优秀的非对映选择 性. 对不同取代基的氮杂研究表明它们均取得了良好的 收率和非对映选择性.

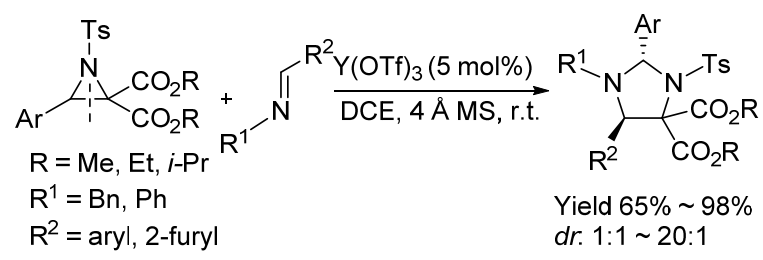

\section{4 氮杂环丙烷与含 $\mathrm{C} \equiv \mathrm{N}$ 类化合物的反应}

氮杂环丙烷与腈类化合物的 $[3+2]$ 环加成反应通常 涉及到氮杂环 $\mathrm{C}-\mathrm{N}$ 键的断裂, 研究发现一系列的路易 斯酸, 如 $\mathrm{BF}_{3} \cdot \mathrm{OEt}_{2}, \mathrm{ZnX}_{2}(\mathrm{X}=\mathrm{Cl}, \mathrm{Br}, \mathrm{I}), \mathrm{Zn}(\mathrm{OTf})_{2}$, $\mathrm{Sc}(\mathrm{OTf})_{3}, \mathrm{Bi}(\mathrm{OTf})_{3}$ 和 $\mathrm{Cu}(\mathrm{OTf})_{2}$ 都能应用到此反应中. 2005 年, Yadav 课题组 ${ }^{[20]}$ 使用 $\mathrm{BF}_{3} \cdot \mathrm{Et}_{2} \mathrm{O}$ 催化腈化物与氮 杂环丙烷的环加成反应(Eq. 14), 该研究使用的氮杂环 丙烷环支链上连有四丁基二苯基硅甲基，该基团通过硅 
的 $\beta$ 位可进一步稳定氮杂环结构. 通过对腈类化合物广 普性研究表明产物收率可达到 $82 \% \sim 90 \%$ ，接着将氮杂 环丙烷扩展到氮杂环丁烷, 也可实现 $[4+2]$ 环加成, 考察 三种腈类都可得到中等到良好的收率.

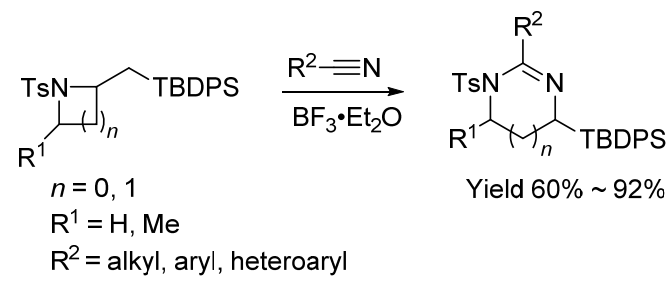

2006 年, Ghorai 课题组 ${ }^{[21]}$ 报道了 $\mathrm{Cu}(\mathrm{OTf})_{2}$ 催化作用 下, 氮杂环丙烷与腈的 [3+2]环加成反应(Eq. 15), 通过 对不同种类路易斯酸的篮选研究表明, $\mathrm{Cu}(\mathrm{OTf})_{2}$ 是一种 比较高效的催化剂. 对于氮杂环丙烷广普性研究表明, 含有 $\alpha$-烷基、芳基和环烷基的氮杂环丙烷与腈的反应， 收率可达到 $61 \%$ ～91\%.

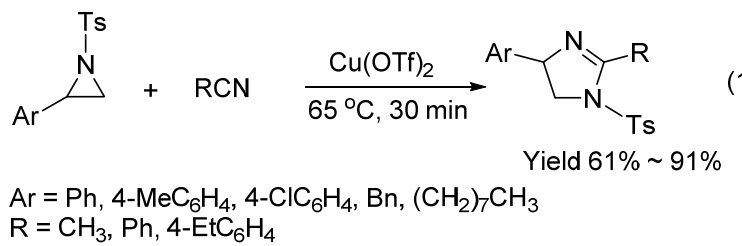

2006 年, 吴劼课题组 ${ }^{[22]}$ 在无溶剂温和的条件下使 用 $\mathrm{Sc}(\mathrm{OTf})_{3}$ 作催化剂研究了 $N$-对甲苯磺酰基氮杂环丙 烷与腈的 $[3+2]$ 环加成反应(Eq. 16). 该方法在室温空气 中进行, 且没有副反应发生; 对底物广普性研究表明反 应都可得到中等到优秀的收率，最高可达 $94 \%$.

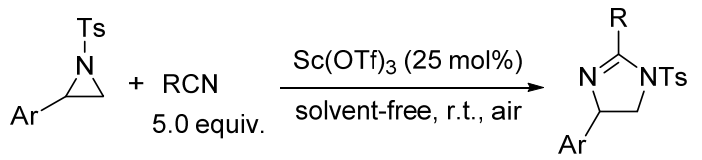

$$
\begin{aligned}
& \mathrm{Ar}=\mathrm{Ph}, 4-\mathrm{ClC}_{6} \mathrm{H}_{4}, 4-\mathrm{MeC}_{6} \mathrm{H}_{4} \quad \text { Yied } 54 \% \sim 94 \% \\
& \mathrm{R}=\mathrm{Me}, \mathrm{Bn}, n-\mathrm{Pr}, \mathrm{Ar}
\end{aligned}
$$

2008 年, Yadav 课题组 ${ }^{[23]}$ 使用固体负载型催化剂:

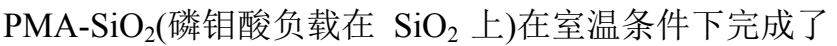
2 -苯基- $N$-对甲苯磺酰基氮杂环丙烷与一系列腈类化合 物的 $[3+2]$ 环加成反应(Eq. 17). $\mathrm{PMA}-\mathrm{SiO}_{2}$ 是一种稳定、 防潮且具有高活性的固体催化剂, 反应完成后, 该催化

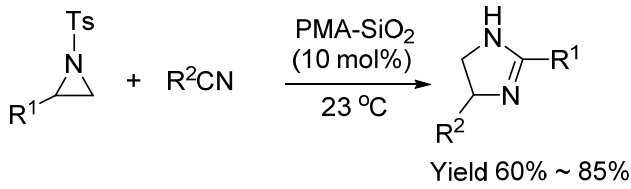

$\mathrm{R}^{1}=\mathrm{Ph}, \mathrm{Bn}, 4-\mathrm{MeOC}_{6} \mathrm{H}_{4}, \mathrm{Cy}, 2$-naphthyl, 1-hexyl, 1-octyl $\mathrm{R}^{2}=\mathrm{Me}, \mathrm{Et}, \mathrm{Ph}, \mathrm{Bn}$
剂通过简单的过滤就能回收再用. 对底物广普性研究表 明产物可得到中等到良好的收率.

2011 年, 魏文珑课题组 ${ }^{[24]}$ 报道了用 $\mathrm{Bi}(\mathrm{OTf})_{3}$ 作催化 剂催化 $N$-对甲苯磺酰基氮杂环丙烷与腈的 [3+2]环加成 反应(Eq. 18), 该方法条件温和, 且 $\mathrm{Bi}(\mathrm{OTf})_{3}$ 对水稳定. 对底物广普性研究表明所笁底物都可得到良好到优秀 的收率.

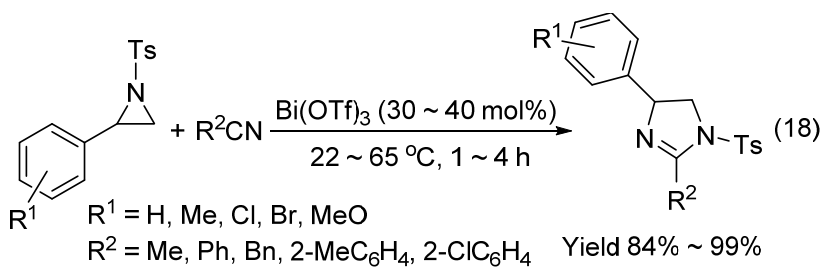

2014 年, Hanamoto 课题组 ${ }^{[25]}$ 报道了使用 $\mathrm{TiF}_{4}$ 作催 化剂催化 2-三氟甲基- $N$-对甲苯磺酰基氮杂环丙烷与腈 的[3+2]环加成反应(Eq. 19). 该反应使用 DCE 作溶剂, 在 $80{ }^{\circ} \mathrm{C}$ 条件下进行, 由于氮杂连有强吸电子基三氟甲 基，从而影响产物的区域选择性使反应得到单一构型的 产物. 对底物广普性研究表明所考察底物大部分都得到 了良好的收率.

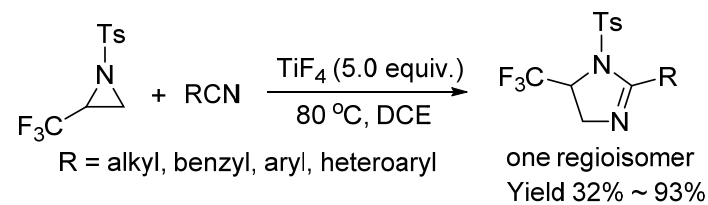

\section{5 氮杂环丙烷与含 $\mathrm{C}=\mathrm{O}$ 化合物的反应}

2007 年, Ghorai 课题组 ${ }^{[26]}$ 通过使用 $\mathrm{Cu}(\mathrm{OTf})_{2}$ 促进 2 -芳基- $N$-对甲苯磺酰基氮杂环丙烷与羰基化合物反应 制得一系列 1,3-噁唑烷(Eq. 20), 该反应在 DCM 溶剂中, 于 $0{ }^{\circ} \mathrm{C}$ 条件下进行, 对底物广普性的考察表明各种脂 肪族和芳香族羰基化合物参与反应时都表现出中等到 优秀的收率和中等及以下的对映选择性，且醛类化合物 的对映选择性比酮类更高.

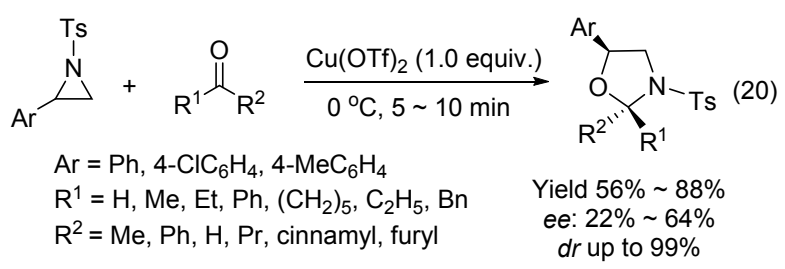

2009 年, Nguyen 课题组 ${ }^{[27]}$ 使用 $\operatorname{Sc}(\mathrm{OTf})_{3}$ 催化 2-烷 基- $N$-对甲苯磺酰基氮杂环丙烷分别与醛或酮的 [3+2] 环加成反应来合成 5-烷基-1,3-噁唑烷(Eq. 21), 对底物 广普性研究表明所考察底物都得到中等到良好的收率. 对醛来说，2-呋喃甲醛、间甲氧基和间羟基苯甲醛的区 域选择性最好，当 C-2 位置上只为甲基时，由于其弱电 
子效应, 氮杂与小体积醛反应时产物总是两个比例相近 的同分异构体; 对于酮来说, 大多都能得到高收率的产 物, 然而当它们与取代基体积大的氮杂反应时所需时间 长, 且产物收率和区域选择性都降低.
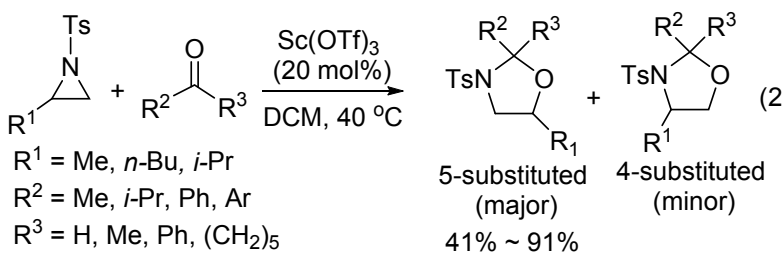

2011 年, 王彦广课题组 ${ }^{[18]}$ 使用 $\mathrm{Zn}(\mathrm{OTf})_{2}$ 催化氮杂 环丙烷经 $\mathrm{C}-\mathrm{C}$ 键断裂与芳香醛的 $[3+2]$ 环加成反应 (Eq. 22). 该反应以 1,2-二氯乙烷作溶剂, $4 \AA \mathrm{MS}$ 作添加 剂于 $50{ }^{\circ} \mathrm{C}$ 条件下反应, 所考察的 20 种底物均取得了中 等到优秀的收率，且产物以顺式为主.

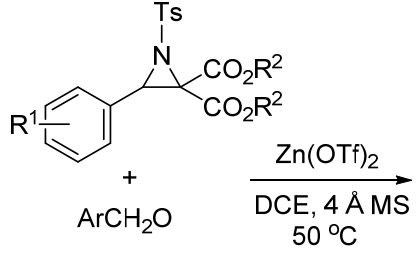

$\mathrm{R}^{1}=\mathrm{H}, 4-\mathrm{Me}, 2-\mathrm{Br}, 3-\mathrm{Br}$ $\mathrm{R}^{2}=\mathrm{Me}, \mathrm{Et}$

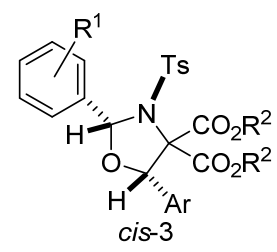

Yield: $52 \% \sim 97 \%$
2011 年, Hanamoto 课题组 ${ }^{[28]}$ 用 $\mathrm{AgSbF}_{6}$ 作催化剂催 化 2-三氟甲基- $N$-对甲苯磺酰基氮杂环丙烷与醛的 [3+ 2]环加成反应，反应主要得到顺式 1,3-䜿唑烷产物(Eq. 23 ), 收率可达到 91\%, 且具有优秀的区域选择性. 对醛 底物的扩展发现缺电子芳香醛的收率优于富电子芳香 醛, 直链脂肪醛只得到中等的收率, 而支链脂肪醛收率 较高. 值得注意的是, 所有反应仅得到一种异构体, 这 应该归功于氮杂 2 位上三氟甲基官能团具有强的吸电子 性和空间位阻效应.

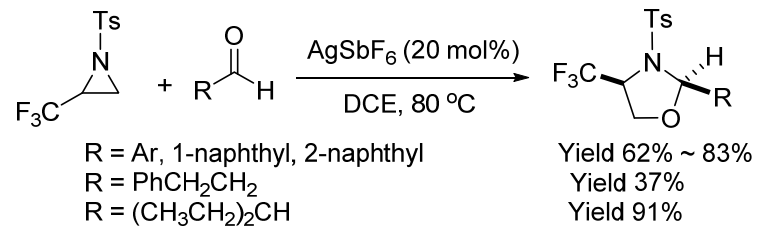

2011 年, 张俊良课题组 ${ }^{[29]}$ 报道了 $\mathrm{Ni}\left(\mathrm{ClO}_{4}\right)_{2} \cdot 6 \mathrm{H}_{2} \mathrm{O}$ 作 催化剂催化氮杂环丙烷经 $\mathrm{C}-\mathrm{C}$ 键断裂与醛的 $[3+2]$ 环 加成反应(Eq. 24), 该反应以甲苯作溶剂, $4 \AA \mathrm{MS}$ 作添 加剂于室温下进行, 取得了高的非对映选择性和区域选 择性, 收率也高达 $99 \%$. 在对醛底物的扩展中发现, 富 电子芳香醛反应效果优于缺电子芳香醛，而在对氮杂环 丙烷底物的扩展中可以看出芳香氮杂环丙烷酯基后所 连接的基团无论是吸电子基还是给电子基, 反应均能取
得很高的收率.

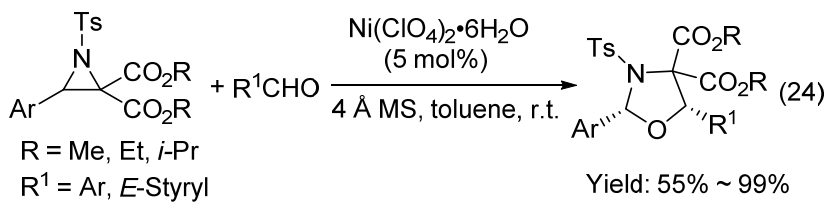

2014 年, Yang 课题组 ${ }^{[30]}$ 报道了使用 $\mathrm{BF}_{3} \cdot \mathrm{OEt}_{2}$ 促进 富勒烯氮杂环丙烷与不同羰基化合物反应制备富勒烯 噁唑烷的反应(Scheme 7), 其中甲酸乙酯参与反应时得 到了不带取代基的富勒烯啞唑烷. 该反应在室温条件下 反应 $15 \sim 60 \mathrm{~min}$, 所考察的底物都可取得中等到优秀 (56\% 93\%)的收率.
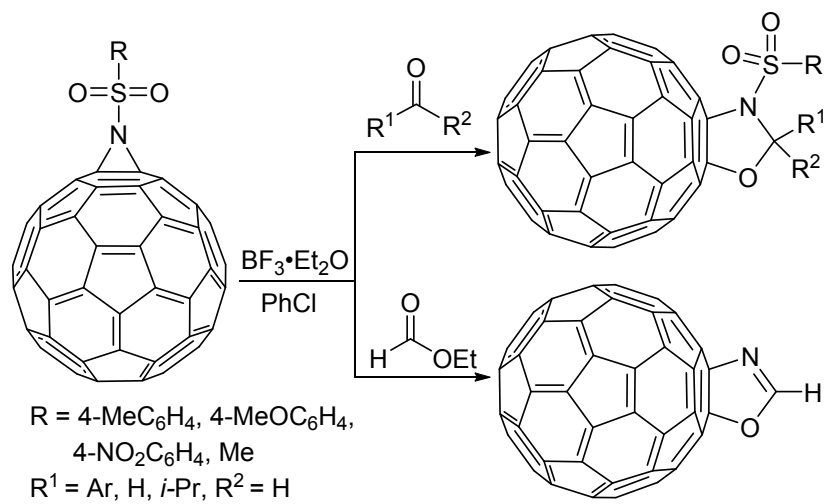

图式 $7 \mathrm{BF}_{3} \cdot \mathrm{OEt}_{2}$ 催化富勒烯氮杂环丙烷与不同羰基化合物 的反应

Scheme $7 \quad \mathrm{BF} 3 \cdot \mathrm{OEt}_{2}$-catalyzed formal [3+2] cycloadditions of aziridines with carbonyl compounds

\section{6 氮杂环丙烷与 $\mathrm{CO}_{2}$ 的反应}

何良年课题组 ${ }^{[31 ~ 33]}$ 分别于 2008 年, 2009 年和 2013 年报道了三种催化剂 $\mathrm{PEG}_{6000}-\left(\mathrm{NBu}_{3} \mathrm{Br}\right)_{2}$ (溴化钾铵盐绑 定到聚乙二醇)、二氯氧化锆和 PEG 功能化的离子液体 (ILs)在氮杂环丙烷与 $\mathrm{CO}_{2}$ 反应中的应用(Eq. 25). 这三 种催化剂都表现出良好的催化活性，在无溶剂和其它辅 助催化剂存在的条件下, 可顺利促进氮杂环丙烷与 $\mathrm{CO}_{2}$ 的反应，所考察的底物都取得了好的收率和区域选择 性; 而且这三种催化剂都可回收再用，且保留了好的催 化活性和区域选择性.

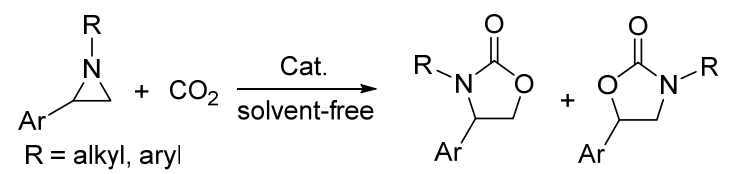

Cat.: $\mathrm{PEG}_{6000}-\left(\mathrm{NBu}_{3} \mathrm{Br}\right)_{2}(0.25 \mathrm{~mol} \%)$, Yield $59 \% \sim 99 \%$ $\mathrm{CO}_{2}: 8 \mathrm{MPa}, 100^{\circ} \mathrm{C}$

Regioselectivity: 86:14 100

Cat:: $\mathrm{ZrOCl}_{2} \cdot 8 \mathrm{H}_{2} \mathrm{O}(5 \mathrm{~mol} \%)$ $\mathrm{CO}_{2}: 6 \mathrm{MPa}, 100^{\circ} \mathrm{C}$

Yield: $52 \% \sim 97 \%$

Regioselectivity: 86:13 99:1

Cat.: BrDBNPEG ${ }_{150} \operatorname{DBNBr}(1 \mathrm{~mol} \%)$, Yield: $60 \%$ 96\% $\mathrm{CO}_{2}: 3 \mathrm{MPa}, 120^{\circ} \mathrm{C}$
Regioselectivity: 96:4 99:1 
2010 年, 何良年课题组 ${ }^{[34]}$ 在没有任何催化剂和有 机溶剂的条件下, 利用超临界 $\mathrm{CO}_{2}$, 通过调节其压力和 温度, 完成了氮杂环丙烷与 $\mathrm{CO}_{2}$ 的反应(Eq. 26). 广普性 研究表明对于不同的氮杂环丙烷反应都得到了高的化 学和区域选择性, 并且也得到了中等到优秀的收率, 但 当 $\mathrm{N}$ 上 $\mathrm{R}^{2}$ 为脂肪基时, 反应收率则会降低. 另外, 通过 调节 $\mathrm{CO}_{2}$ 的压力可以改变反应的化学选择性, 当 $\mathrm{CO}_{2}$ 压 力为 $9.0 \mathrm{MPa}$ 时, 更利于合成 5-芳基-2-噁唑烷酮.

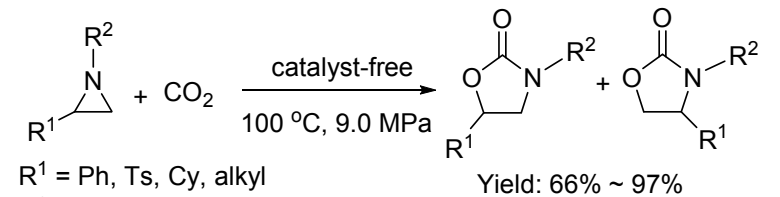

2011 年, Pinhas 课题组 ${ }^{[35]}$ 报道了干冰与氮杂环丙烷 的反应(Eq. 27). 该反应不需要任何催化剂, 也不需要高 温或者高压, 在室温条件下, 以 THF 作溶剂或者在无溶 剂条件下, 在高速球磨作用下就可取得好的结果. 广普 性研究表明收率最高能达到 $100 \%$, 当 $\mathrm{R}^{2}$ 为苯基时反应 以产物 $\mathbf{A}$ 为主, $\mathrm{R}^{2}$ 为烷基时反应以产物 $\mathbf{B}$ 为主; 另外, 氮杂的 $\mathrm{R}^{1}$ 为苯基、 $3-\mathrm{MeC}_{6} \mathrm{H}_{4}$ 或烷基时，基本无目标产 物.

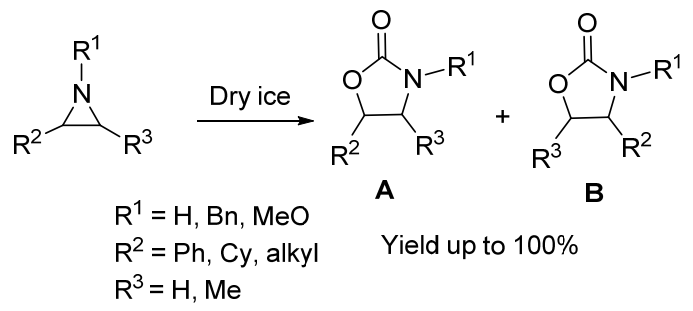

2011 年, 刘国生课题组 ${ }^{[36]}$ 利用 1,5-二氮杂双环 [4.3.0]壬-5-烯(DBN) 快速固定 $\mathrm{CO}_{2}$ 形成一种碳酸氢盐, 接着使其与氮杂环丙烷反应生成啞唑烷酮类化合物(Eq. 28). 该反应在 $101 \mathrm{kPa}$ 二氧化碳氛围下, 以 $10 \mathrm{~mol} \%$ DBN 作催化剂, $20 \mathrm{~mol} \% \mathrm{LiI}$ 作辅助催化剂, 甲苯作溶剂 的条件下进行. 对于 $\mathrm{N}$ 上不同取代基的氮杂环, 大部分 反应都取得了较好的收率, 但 $N$-对甲苯磺酰基保护的 氮杂环丙烷没有得到期望的产物.

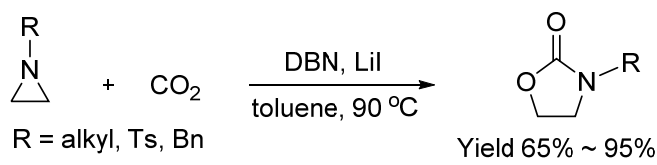

2011 年, Aggarwal 课题组 ${ }^{[37]}$ 完成了在钯催化剂作用 下 2-烯丙基氮杂环丙烷与周围大气中 $\mathrm{CO}_{2}$ 发生反应生 成噁唑烷酮类化合物的反应(Eq. 29). 对于多数氮杂, 该 方法具有高的收率和区域选择性，而对于未被取代的氮 杂或 $\mathrm{R}^{1}$ 是供电子基时, 在无 TBAT 条件下, 产物收率更
高.

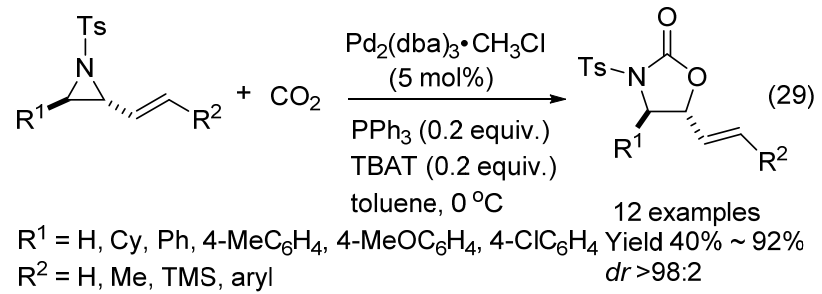

2012 年, Chai 课题组 ${ }^{[38]}$ 报道了氮杂环卡宾(NHC)催 化作用下 $\mathrm{CO}_{2}$ 与 $N$-对甲苯磺酰基氮杂环丙烷的反应(Eq. $30)$. 广普性研究表明 2-芳基取代的氮杂反应得到良好 到优秀的收率以及良好的区域选择性；2-丁基取代的氮 杂反应也有 $70 \%$ 的收率和中等的区域选择性。

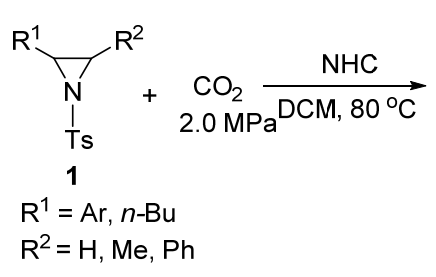

2013 年, Ikariya 课题组 ${ }^{[39]}$ 利用 $\mathrm{NHC}-\mathrm{CO}_{2}$ 加合物作 催化剂来催化 $\mathrm{CO}_{2}$ 与氮杂环丙烷的反应(Eq. 31). NHC$\mathrm{CO}_{2}$ 加合物是将 $\mathrm{CO}_{2}$ 加载到氮杂环卡宾 $(\mathrm{NHC})$ 上形成的 咪唑-2-羧酸化合物, 可以促进 $\mathrm{CO}_{2}$ 亲核进攻不同取代 基的氮杂，得到的产物具有中等到优秀的收率和高的选 择性，另外催化剂可以重复使用五次且活性不受影响.

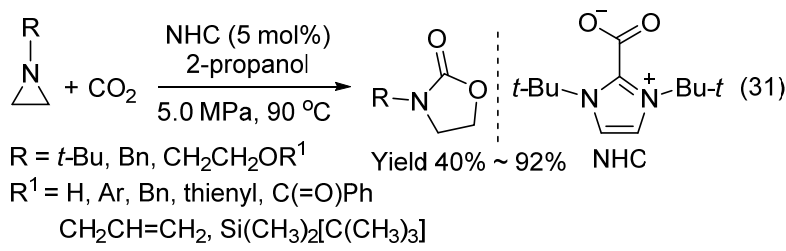

2014 年, Bhanage 课题组 ${ }^{[40]}$ 使用直链胺功能化的 MCM-41 作催化剂催化 $\mathrm{CO}_{2}$ 与氮杂环丙烷偶合得到相 应的 5 芳基-2-噁唑烷酮的反应(Eq. 32). 该反应是在无 溶剂、5.0 MPa 压力下, $40{ }^{\circ} \mathrm{C}$ 条件下进行的, 对于不同 取代基的氮杂进行扩展得到的产物具有中等到优秀的 收率和优秀的区域选择性. 此外, 催化剂连续使用五次 后催化活性和选择性都没有大的降低.

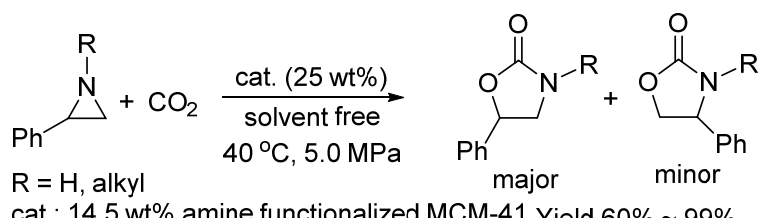


2015 年, 彭新文课题组 ${ }^{[41]}$ 利用 SCB/KI 催化体系成 功催化了 $\mathrm{CO}_{2}$ 与氮杂环丙烷在无溶条件下的环加成反 应(Eq. 33). 底物广普性研究表明多种氮杂均取得较好 的收率及高的化学和区域选择性, 但 $\mathrm{N}$ 上连有环己基的 氮杂收率仅有 $10 \%$. 该催化剂重复利用三次后反应活性 基本没变.

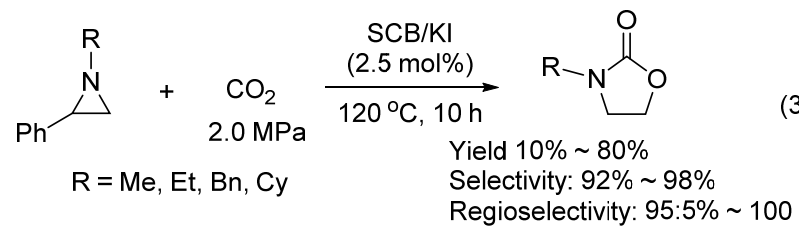

\section{7 氮杂环丙烷与含 $\mathrm{C}=\mathrm{S}$ 化合物的反应}

2008 年, 侯雪龙课题组 ${ }^{[2]}$ 使用三丁基膦作催化剂 实现了氮杂环丙烷分别与二硫化碳、异硫氰酸酯的环加 成反应(Scheme 8$)$, 该反应为合成噻唑啉酮类化合物提 供了一种简单而便捷的方法. 底物广普性研究表明各种 氮杂环丙烷与二硫化碳、异硫氰酸酯的环加成反应都可 顺利进行, 各种环已基取代的氮杂都能取得较好的收 率, 其它脂肪族氮杂环因空间位阻等原因收率较低, 含 苯基的氮杂环因电子效应和空间效应影响得到了等量 的对映体. 同时作者对该反应机理作了预测: 首先有机 膦进攻二硫化碳形成两性离子 $\mathbf{A}$, 然后 $\mathbf{A}$ 再与氮杂环丙 烷反应生成中间体 $\mathbf{B}$, 最后 $\mathbf{A}$ 发生关环形成产物, 而三 丁基膦再生进入下一个催化循环(Scheme 9).

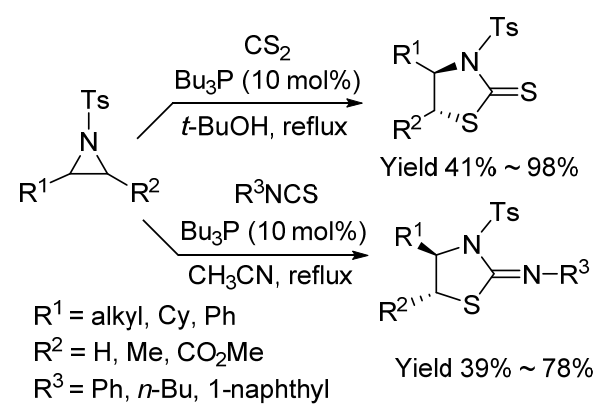

图式 8 三丁基膦催化氮杂环丙烷与二硫化碳、异硫氰酸酯的 环加成反应

Scheme 8 Tributylphosphine-catalyzed formal [3+2] cycloadditions of aziridines with carbon disulfide and isothiocyanate

2009 年, 徐家喜课题组 ${ }^{[43]}$ 在 THF 溶剂中于 $80{ }^{\circ} \mathrm{C}$ 回 流条件下完成了氮杂环丙烷与二硫化碳的反应(Eq. 34). 研究发现脂肪族氮杂环丙烷作底物具有较好的区域选 择性，产物以(S)-4-苯基噻唑烷-2-硫酮为主，且具有中 等到良好的收率，而苯乙烯氮杂在相同条件下得到了比 例是 $1: 4$ 的 $(S)$-4-苯基噻唑烷-2-硫酮和 $(R)$-5-苯基噻唑 烷-2-硫酮, 相应的 6-氮杂双环[3.1.0]正己烷由于位阻效 应而无法参与反应.

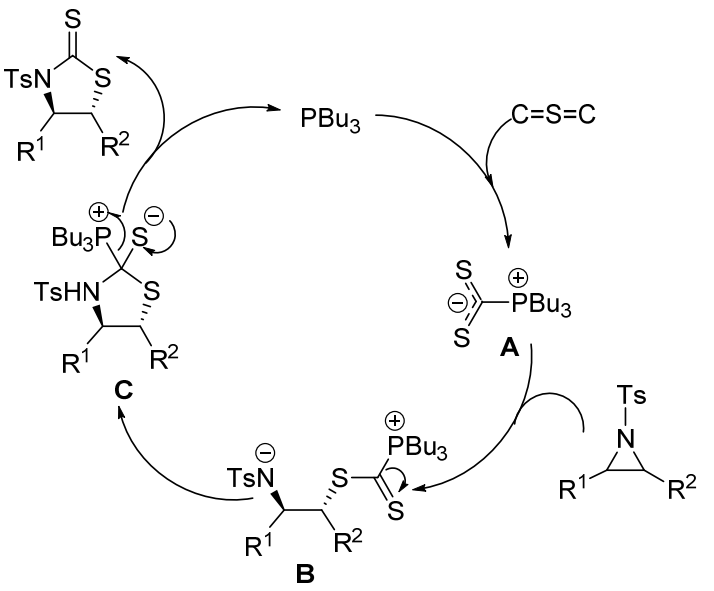

图式 9 氮杂环丙烷与二硫化碳反应推测的机理

Scheme 9 Plausible mechanism of the P-catalyzed reaction of aziridine with $\mathrm{CS}_{2}$

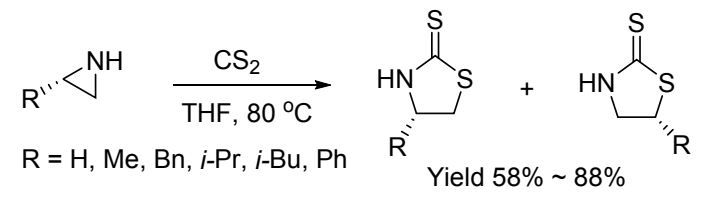

\section{8 氮杂环丙烷与含 $\mathrm{C}=\mathrm{Se}$ 化合物的反应}

2013 年, Punniyamurthy 课题组 ${ }^{[44]}$ 报道了使用 $\mathrm{Fe}\left(\mathrm{NO}_{3}\right)_{3} \cdot 9 \mathrm{H}_{2} \mathrm{O}$ 催化氮杂环丙烷与异硒氧酸酯的环加成 反应(Eq. 35). 该反应使用 $\mathrm{Fe}\left(\mathrm{NO}_{3}\right)_{3} \cdot 9 \mathrm{H}_{2} \mathrm{O}$ 作催化剂, 水 作溶剂于 $60{ }^{\circ} \mathrm{C}$ 条件下反应就可得到理想收率的产物. 对异硒氰酸酯广普性研究表明, 不管是带有吸电子基或 供电子基的苯基异硒氧酸酯还是 1-菜基或 2-芴基异硒 氧酸酯, 反应均取得了中等到优秀的收率; 对于氮杂广 普性研究表明，当 $\mathrm{N}$ 原子上连有 $\mathrm{Bz}$ 或 Boc 保护基时, 无 目标产物生成，而当 $\mathrm{N}$ 原子上无取代基或者连有供电子 基时, 反应均取得了良好到优秀的收率.

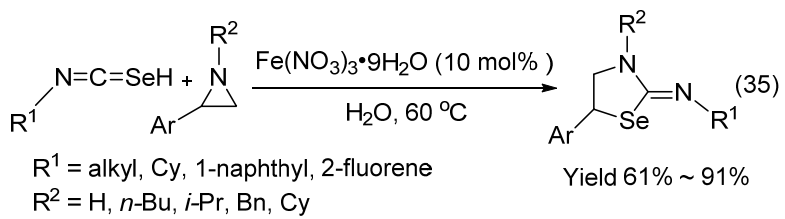

\section{9 氮杂环丙烷与含 $N=N$ 化合物的反应}

2008 年, 王彦广课题组 ${ }^{[45]}$ 报道了偶氮化合物与 2-羰基 氮杂环丙烷的环加成反应(Eq. 36). 该反应以 2-羰基氮 杂环丙烷和偶氮二甲酸二乙酯作标准底物, 经优化篮选 得出催化剂三苯基膦用量为 1.3 equiv., 甲苯作溶剂, 在 氮气保护下回流 $2 \mathrm{~h}$, 标准底物可得到 99\%的收率. 普 适性考察表明 17 种底物反应都得到很高的收率 $(\geqslant$ $92 \%)$. 随后作者通过副产物的分离以及重氢标记的实 
验对反应机理进行了验证，即三苯基膦首先与偶氮二甲 酸二乙酯结合形成两性离子, 然后再与 2-羰基氮杂环 丙烷反应形成高收率的吡唑啉产物.

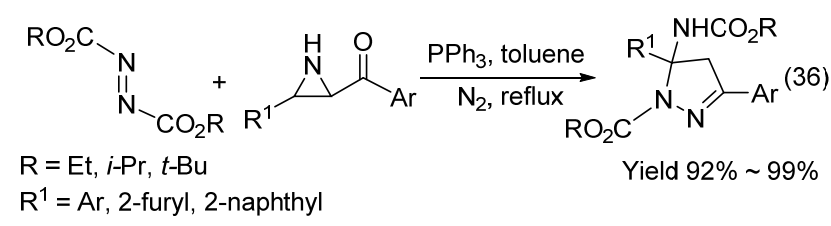

\subsection{0 氮杂环丙烷与含 $C-C$ 化合物的反应}

2010 年, Ghorai 课题组 ${ }^{[46]}$ 实现了采用氮杂环丙烷作 原料, 通过多米诺一开环一关环反应(DROC)来合成手性 $\gamma$-内酰胺的想法(Eq. 37). 氮杂环丙烷在 $\mathrm{Cu}(\mathrm{OTf})_{2}$ 催化作 用下与丙二酸二乙酯或乙酰乙酸乙酯发生 $\mathrm{S}_{\mathrm{N}} 2$ 型开环反 应，接着发生分子内酰胺化反应得到相应的 $\gamma$-内酰胺, 其中碱 $\mathrm{NaH}$ 作为助剂提高了烯醇化物的亲核性. 对底 物广普性研究表明反应均得到中等到优秀的收率和优 秀的对映选择性.
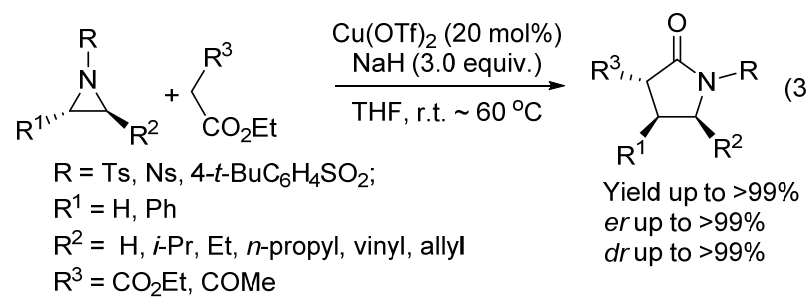

2013 年, Ghorai 课题组 ${ }^{[47]}$ 报道了采用丙二腈作原 料, 通过多米诺一开环一环化反应(DROC)与氮杂环丙烷 反应来制备各种官能团取代的 4,5-二氢吡咯(Eq. 38). 首 先氮杂环丙烷在 $\mathrm{Sc}(\mathrm{OTf})_{3}$ 和叔丁醇钾 $(t-\mathrm{BuOK})$ 作用下, 亲核试剂丙二氰对其进攻发生 $\mathrm{S}_{\mathrm{N}} 2$ 型开环反应, 接着发 生分子内环化得到相应的 4,5-二氢吡咯. 对于带不同保 护基的氮杂都有较好到优秀的收率(75\% 99\%)和优秀 的区域选择性，而对于 N-Ns 保护的氮杂，反应得到收 率优秀的单一构型产物.

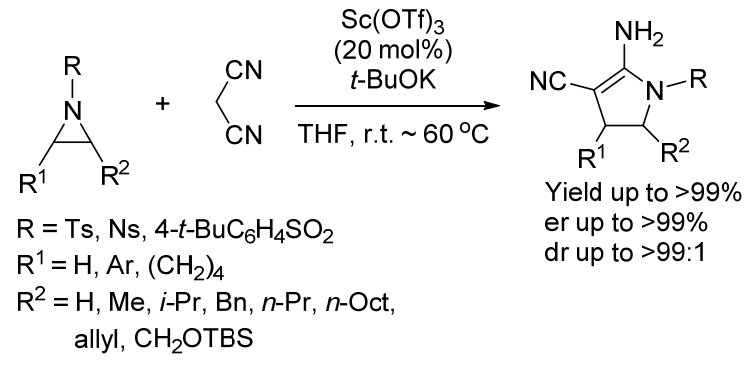

\subsection{1 氮杂环丙烷与含 $X=\cdot=Y$ 化合物的反应}

2006 年, Saito 课题组 ${ }^{[48]}$ 报道了用镍催化剂催化氮 杂环丙烷与异氰酸酯化合物的环加成来制备亚胺基噁 唑烷化合物或咪唑啉酮化合物的反应(Scheme 10). 该
研究以 $\mathrm{NiI}_{2}$ 作催化剂, 甲苯为溶剂, $10{ }^{\circ} \mathrm{C}$ 条件下反应得 到高收率和高选择性的亚胺基啞唑烷衍生物. 不管是正 丁基、叔丁基取代的还是双取代的氮杂，反应可得到高 达 $92 \%$ 的收率，但当反应使用 $N$-对甲苯磺酰基取代的 氮杂作底物时, 反应没有发生. 另外, 作者通过研究发 现，碘化镍不仅能起到催化剂的作用，而且随着反应时 间的增长, 还能使主产物噁唑烷亚胺类衍生物异构化成 咪唑啉酮类衍生物.

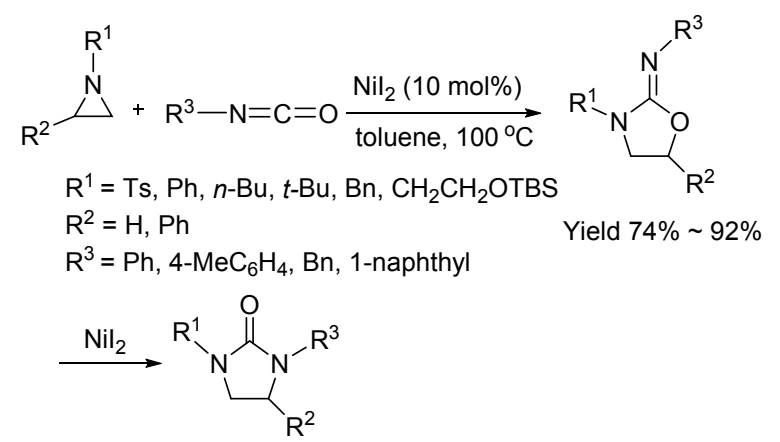

图式 10 镍催化剂催化氮杂环丙烷与异氧酸酯的环加成反应 Scheme 10 Nickel(II) iodide-catalyzed formal [3+2] cycloadditions of aziridines with isocyanates

2013 年, Punniyamurthy 课题组 ${ }^{[44]}$ 报道了 $\mathrm{Fe}\left(\mathrm{NO}_{3}\right)_{3}$ • $9 \mathrm{H}_{2} \mathrm{O}$ 催化的氮杂环丙烷与异硒氰酸酯的环加成反应 (Eq. 39). 该反应以 1-异丙基-2-苯乙烷氮杂环丙烷与苯 基异硒氰酸酯作标准底物，通过条件优化得出：催化剂 $\mathrm{Fe}\left(\mathrm{NO}_{3}\right)_{3} \cdot 9 \mathrm{H}_{2} \mathrm{O}$ 用量为 $10 \mathrm{~mol} \%$, 溶剂水用量为 $1 \mathrm{~mL}$, 在 $60{ }^{\circ} \mathrm{C}$ 条件下反应标准底物可完全转化成所需产物. 底物广普性研究表明, 所有底物均能取得理想的收率.

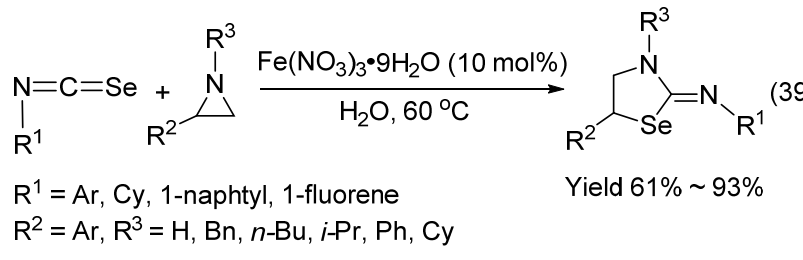

2014 年, Punniyamurthy 课题组 ${ }^{[49]}$ 报道了使用四氢 吡咯有效地催化氮杂环丙烷与异硫氰酸酯的反应(Eq. 40). 通过对反应条件优化篮选得出在水作溶剂, 催化 剂用量为 $25 \mathrm{~mol} \%$, 温度为 $50{ }^{\circ} \mathrm{C}$ 的条件下, 标准底物 $N$-异丙基-2-苯乙烷氮杂环丙烷 $(0.5 \mathrm{mmol})$ 与苯基异硫氰 酸酯反应得到 $97 \%$ 的收率; 接下来对 $\mathrm{N}$ 上连有烯丙基、 苄基、正丁基以及环已基的芳基氮杂进行考察，它们均 取得了中等到较好的收率，而 $\mathrm{N}$ 上连有 $\mathrm{Ts}$ 时则不发生 反应. 随后又将最佳条件应用于二硫化碳和异硒氰酸酯 的扩展上，反应都取得了理想的效果. 作者通过对机理 探究得知: 该反应是在四氢吡咯催化作用下经历一个尿 素型中间过渡态，再经历一个 $\mathrm{S}_{\mathrm{N}} 2$ 反应历程来得到构型 反转的产物. 


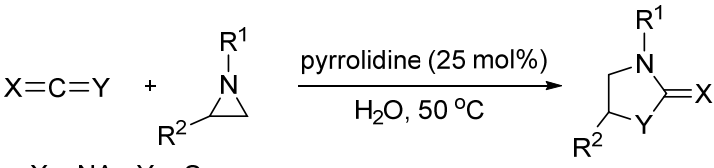

$$
\begin{aligned}
& \mathrm{X}=\mathrm{NAr}, \mathrm{Y}=\mathrm{S} \text {; } \\
& \mathrm{R}^{1}=\text { allyl, Bn, } n \text {-Bu, Cy, } \mathrm{R}^{2}=\mathrm{Ph} \quad \text { Yield } 69 \% \sim 97 \% \\
& \mathrm{R}^{1}=i-\mathrm{Pr}, \mathrm{R}^{2}=\mathrm{Ar} \quad \text { Yield } 73 \% \sim 89 \% \\
& \mathrm{X}=\mathrm{NAr}, \mathrm{Y}=\mathrm{Se} ; \mathrm{R}^{1}=i-\mathrm{Pr}, \mathrm{R}^{2}=\mathrm{Ph} \quad \text { Yield } 83 \% \sim 91 \% \\
& \mathrm{X}=\mathrm{S}, \mathrm{Y}=\mathrm{S} ; \mathrm{R}^{1}=i-\operatorname{Pr}, \mathrm{R}^{2}=\mathrm{Ar} \quad \text { Yield } 73 \% \sim 81 \%
\end{aligned}
$$

2014 年, Stoltz 课题组 ${ }^{[50]}$ 报道了第一例底物诱导的 $\mathrm{ZnBr}_{2}$ 促进的关于 $\mathrm{N}-\mathrm{H}$ 和 $N$-对甲苯磺酰基氮杂环丙烷 分别与累积二烯烃的 $[3+2]$ 环加成反应(Eq. 41). 在 $\mathrm{ZnBr}_{2}$ 的促进作用下, 含有不同取代基(烷基、甲硅烷基 以及芳基)的氮杂环丙烷与芳基累积二烯烃反应来制备 亚氨基咪唑烷和亚氨基噁唑烷, 都可以得到中等到良好 的收率.

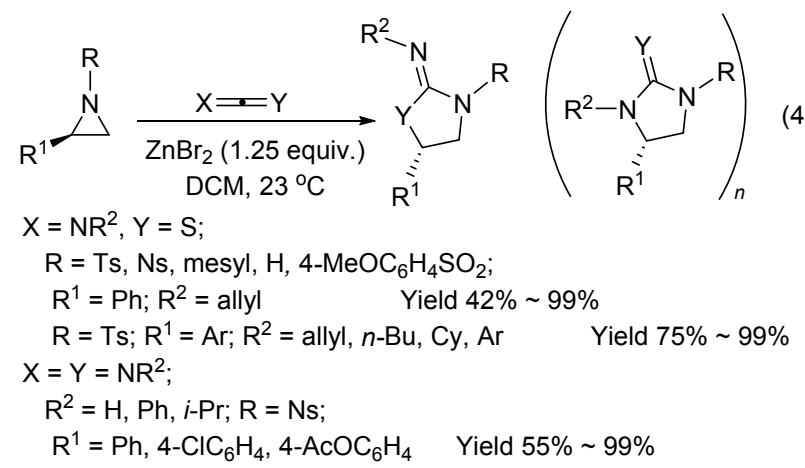

\section{2 氮杂环丙烷 $[3+3]$ 环加成反应}

\section{1 氮杂环丙烷与烯丙基类化合物的反应}

2005 年, Harrity 课题组 ${ }^{[51]}$ 报道了氮杂环丙烷与甲基 烯丙醇通过开环一环化发生 $[3+3]$ 环加成反应得到哌啶 的方法(Scheme 11). 作者首先通过 $n-\mathrm{BuLi}, \mathrm{TMEDA}$ 与 2-甲基烯丙醇在乙醚中反应, 再在 $\mathrm{MgBr}_{2}$ 作用下形成格 氏试剂, 接着与氮杂环丙烷反应得到开环产物 $\mathbf{3}$, 随后

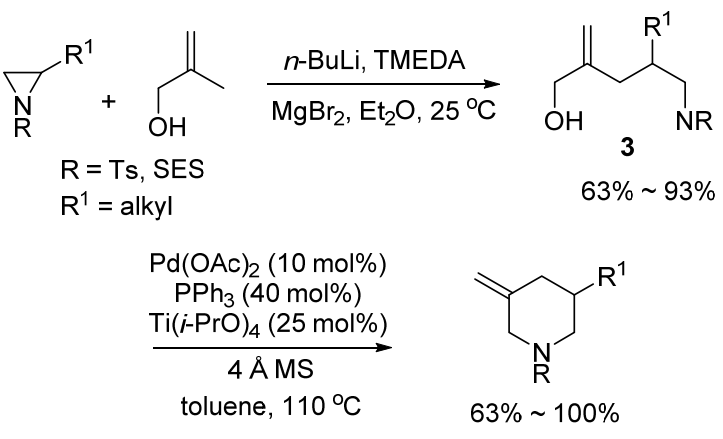

图式 11 氮杂环丙烷与甲基烯丙醇的 [3+3]环加成反应 Scheme $11[3+3]$ cycloadditions of aziridines with methallyl alcohol
在 $\mathrm{Pd}(\mathrm{OAc})_{2}$ 和 $\mathrm{Ti}(i-\mathrm{PrO})_{4}$ 催化作用下, $\mathrm{PPh}_{3}$ 与 $4 \AA \mathrm{MS}$ 作 添加剂, 甲苯作溶剂, $110{ }^{\circ} \mathrm{C}$ 条件下反应得到成环产物 哌啶. 对底物扩展发现 Ts-保护的氮杂有优秀的收率, 而 SES-保护的氮杂仅得到中等的收率.

\section{2 氮杂环丙烷与炔丙基类化合物的反应}

2009 年, 周永贵课题组 ${ }^{[52]}$ 发现不同的 $N$-对甲苯磺 酰基氮杂环丙烷与芳基炔丙基醇在叔丁醇钾 $(t-\mathrm{BuOK})$ 的促进作用下发生开环/关环串联反应，能得到相应的 羟嗪衍生物(Eq. 42). 对芳基炔丙醇和氮杂环丙烷的扩 展研究发现在苯环上带有供电子基( $\mathrm{Me}$ )的炔丙基醇能 得到 $64 \%$ 的收率, 强吸电子基 $\left(\mathrm{CF}_{3}\right)$ 取代的炔丙基醇相 应产物收率为 78\%, 1-䒺、2-噻吩取代的炔丙醇相应收率 分别为 66\%和 70\% ; 对于甲基、异丙基、异丁基取代的 氮杂环丙烷相应收率分布在 $65 \%$ 73\%之间，而茮基取 代的氮杂收率只有 $22 \%$.

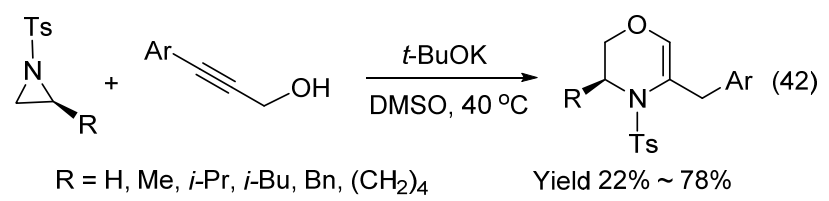

2009 年, Sujit 课题组 ${ }^{[53]}$ 报道了 $\mathrm{Ag}(\mathrm{I})$ 催化剂作用下 炔丙基醇与 $N$-对甲苯磺酰基氮杂环丙烷的串联反应 (Scheme 12). 该反应在银催化作用下, 氮杂环丙烷先与 炔丙醇生成开环产物后再发生环化反应生成最终产物, 通过对照实验发现 $\mathrm{Cs}_{2} \mathrm{CO}_{3}$ 主要起到促进环化反应的作 用. 底物广普性研究表明当 $\mathrm{R}$ 为 $\mathrm{H}$ 时, 产物以七元环产 物为主; 而当 $\mathrm{R}$ 为苯基时, 产物为六元环产物. 他们还 提出了反应机理, 首先氮杂环丙烷在银催化下与炔丙醇 反应得到开环产物 $\mathbf{I}$, 接着银与 $\mathbf{I}$ 的三键配位形成两个 中间体 $\mathrm{A}$ 和 $\mathrm{B}$,中间体 $\mathbf{A}$ 可能经过 7-endo 和 6-exo 两种 模式(path $\mathbf{a}$ 和 path b), 而中间体 B 可能经过 6-exo 和 5-endo (path $\mathbf{c}$ 和 path d). 由 Baldwin 规则可知途径 $\mathbf{b}$ 是 不利的, 实验也验证了只能得到产物 II 和 IV, 虽然途径 d 也符合 Baldwin 规则，但在实验中没有观察到相应产 物的生成.

2009 年, Ghorai 课题组 ${ }^{[54]}$ 使用一种简单实用的方法 来合成各种官能团取代的非外消旋吗啉类化合物及其 同系物(Scheme 13), 即通过 $\mathrm{Cu}(\mathrm{OTf})_{2}$ 催化卤代醇对活 化的氮杂环丙烷进行 $\mathrm{S}_{\mathrm{N}} 2$ 型开环, 接着开环产物在 $\mathrm{KOH}$ 作用下进行分子内关环合成双取代吗啉类化合物， 经过实验验证该方法具有优秀的收率和对映选择性.

\section{3 氮杂环丙烷与联烯酸酯类化合物的反应}

2009 年, Kwon 课题组 ${ }^{[55]}$ 完成在三苯基膦作用下联 烯酸酯与氮杂环丙烷的 $[3+3]$ 环加成反应(Eq. 43), 该法 能得到多官能团化的四氢吡啶. 经过机理验证发现, 得 

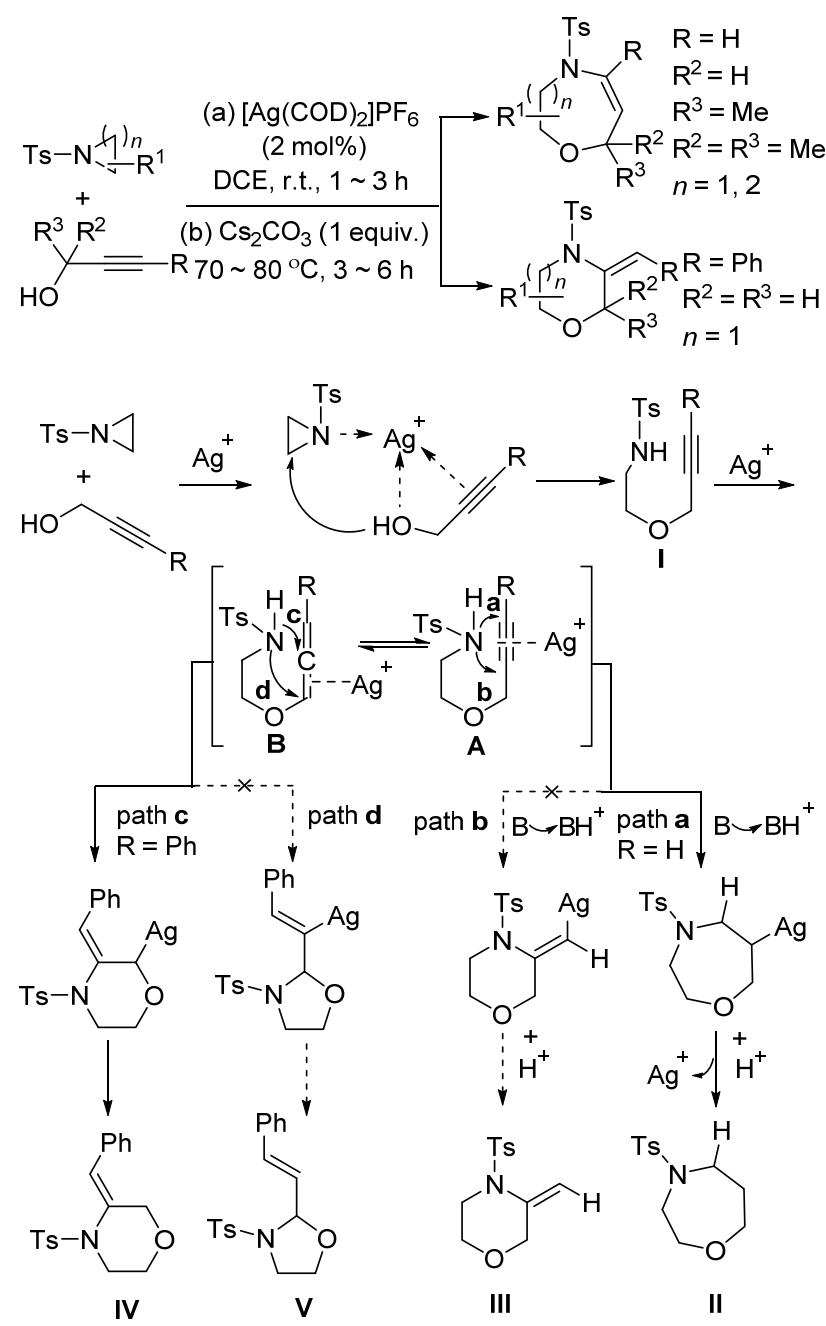

图式 $12 \mathrm{Ag}(\mathrm{I})$ 催化氮杂环丙烷与炔丙基醇的环加成反应

Scheme 12 Silver(I)-catalyzed formal cycloadditions of aziridines with propargylic alcohol

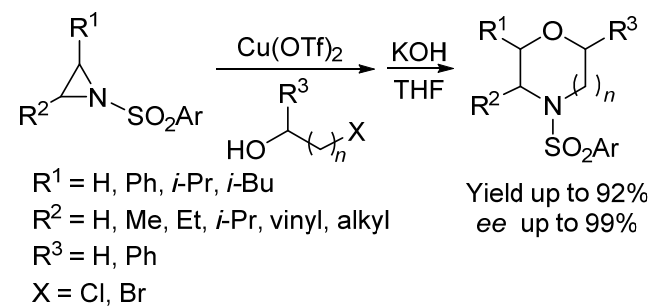

图式 13 氮杂环丙烷与卤代醇的 $[3+3]$ 环加成反应

Scheme 13 [3+3] cycloadditions of aziridines with halogenated alcohols

到的四氢吡啶母环来源于联烯酸酯母环的 $\alpha, \beta$ 和 $\beta^{\prime}$ 而不 是 $\alpha, \beta$ 和 $\gamma$ 碳原子, 联烯酸酯的 $\gamma$ 碳原子最终连到对硝 基苯环上, 释放出 $\mathrm{SO}_{2}$ 后生成产物. 在最优条件下对氮 杂环丙烷进行扩展, 发现芳基氮杂苯环或䒺环的邻、间 或对位上不管带有富电子基还是缺电子基反应都能得 到中等到优秀收率的 1,2-反式非对映异构体.

2011 年, Ghorai 课题组 ${ }^{[56]}$ 完成了 2-溴-4,5-二烷基苯<smiles>[R]OC(=O)C1=CC=C1C(=O)OCC</smiles>

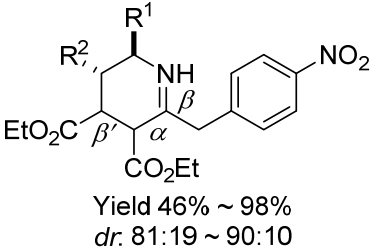

乙腈与 $N$-对甲苯磺酰基氮杂环丙烷反应合成四氢喹啉 衍生物(Eq. 44). 首先 2-溴-4,5-二烷基苯乙腈作为亲核 试剂在叔丁醇钾的作用下对氮杂环丙烷发生 $S_{\mathrm{N}} 2$ 型开 环，接着在钯催化剂作用下发生分子内 $\mathrm{C}-\mathrm{N}$ 环化形成 四氢喹啉衍生物，收率和立体选择性都达到优秀。

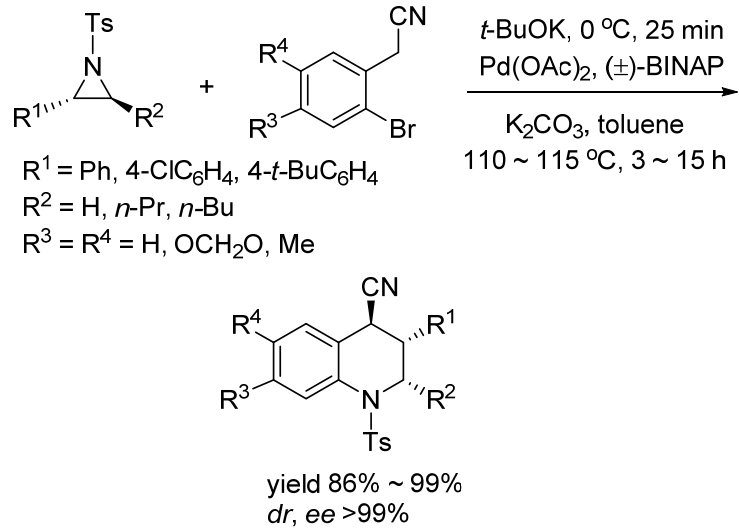

2013 年, 王绍武课题组 ${ }^{[57]}$ 报道了 $\mathrm{Sc}(\mathrm{OTf})_{3}$ 催化 $N$ 烷基-2-吲哚甲醇类以及茮醇类化合物与氮杂环丙烷的 $[3+3]$ 环加成合成四氢 $\beta$-咔啉和四氢异喹啉衍生物的方 法(Scheme 14). 在最优条件下, 对于 $N$-烷基-2-吲哚甲 醇与氮杂的反应进行底物扩展，发现氮杂上取代基为芳 基时有利于氮杂开环进行反应，而脂肪族的氮杂在该条 件下不能反应; 带有吸电子基的苯乙烯氮杂收率高于带 有供电子基的苯乙烯，吲哚取代基 $\mathrm{R}^{1}$ 为末端烯或炔时， 更利于稳定结构得到产物，当吲哚 $\mathrm{N}$ 上取代基 $\mathrm{R}$ 为吸电 子基卤素时，收率会降低. 对于茮基醇与氮杂的反应, 在氮杂苯环上连有吸电子取代基同样比连有供电子 取代基时的收率高，氮杂环上 $\mathrm{N}$ 原子的保护基团为缺电 子基时，反应收率会降低.

2015 年，王锐课题组 ${ }^{[58]}$ 报道了 3-异硫氰基-2-羰基 吲哚与氮杂环丙烷发生的 $[3+3]$ 环加成反应(Scheme 15 ). 研究发现在原位生成的镁试剂与手性配体 $(R)-3,3$ '-F-BINOL 络合形成的催化剂作用下, $N$-(2-甲基 吡啶)-氮杂环丙烷与 3-异硫氰-2-羰基吲哚先发生对映 

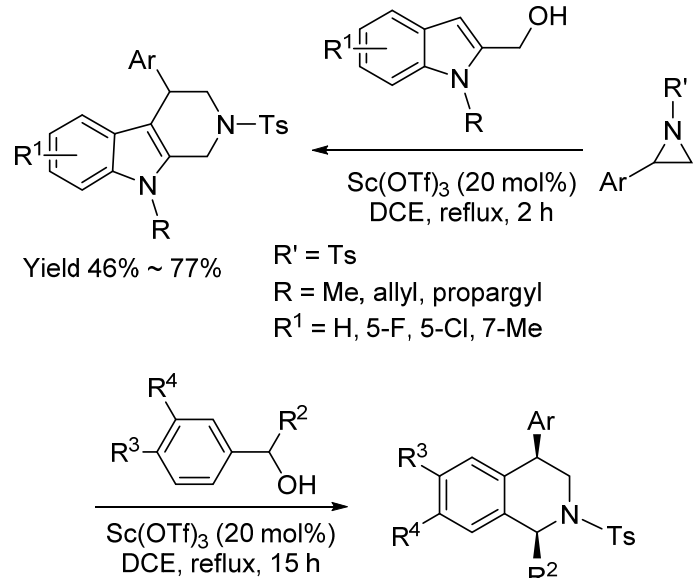

$\mathrm{R}^{\prime}=\mathrm{Ts}, \mathrm{Ns}, 4-t-\mathrm{BuC}_{6} \mathrm{H}_{4} \mathrm{SO}_{2}$

$\mathrm{R}^{2}=\mathrm{H}, \mathrm{Ph}$

$\mathrm{R}^{3}, \mathrm{R}^{4}=\mathrm{MeO}, \mathrm{OCH}_{2} \mathrm{O}$

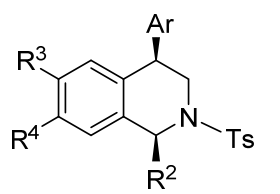

Yield: $38 \% \sim 76 \%$

图式 $14 \mathrm{Sc}(\mathrm{OTf})_{3}$ 催化氮杂环丙烷与 $N$-烷基-2-吲哚甲醇类/ 苄醇类化合物的环加成反应

Scheme $14 \mathrm{Sc}(\mathrm{OTf})_{3}$-catalyzed formal [3+3] cycloadditions of aziridines with 2-indolyl methanols/benzylic alcohols

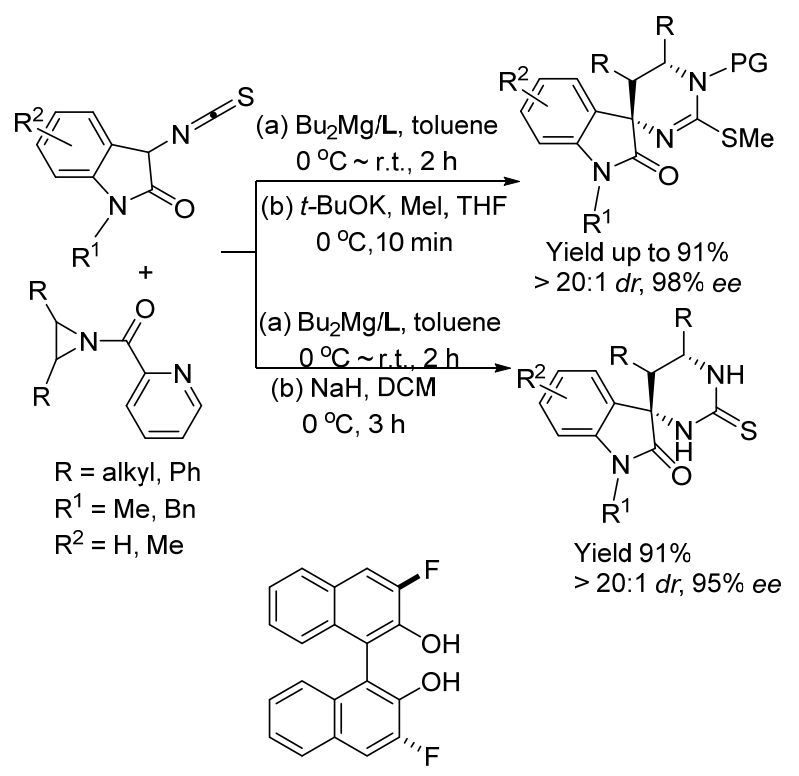

$\mathbf{L}$

图式 15 氮杂环丙烷与 3-异硫氰基-2-羰基吲哚的环加成反应 Scheme $15[3+3]$ cycloadditions of aziridines with 3-isothiocyanato oxindoles

选择性开环反应，接着在碱作用下进一步环化得到六元 杂环化合物. 多数氮杂的开环产物都能得到良好的收率 和优秀的对映选择性, 但是五元氮杂反应活性低, 且收 率只有中等. 关环反应都可以取得优秀的非对映和对映 选择性以及中等到良好的收率.

\section{3 氮杂环丙烷 $[3+4]$ 环加成反应}

2010 年, Alper 课题组 ${ }^{[59]}$ 报道了一种高效一锅法合
成 3,4-二氢-1,4-苯并氧氮杂草-5 $(2 H)$-酮及 3,4-二氢-1,4吡啶并氧氮杂草-5(2H)-酮的的方法(Eq. 45). 该方法利 用 $N$-对甲苯磺酰基氮杂环丙烷与 2-卤代苯酚或 2-卤 代-3-羟基吡啶分别在碱作用下发生 $\mathrm{S}_{\mathrm{N}} 2$ 开环反应，接着 在 $\mathrm{CO}$ 存在 $\mathrm{Pd}$ 催化剂作用下发生羧基酰胺化反应来合 成相应产物. 对不同的氮杂与一系列 2-卤代酚的反应进 行扩展，发现环已烷氮杂与带有苯基或甲基酯取代的 2碘苯酚反应时，比与其它官能团取代的 2-碘苯酚反应的 收率高; 而非环化的氮杂与不同的 2-碘代酚或羟基吡啶 反应时收率为 $64 \% \sim 91 \%$, 且仅得到一种区域选择性的 单一异构体. 2-溴苯酚作原料与各种氮杂的反应可得到 良好到优秀的收率.

$$
\begin{aligned}
& \mathrm{R}=\mathrm{CH}, \mathrm{N} \\
& \mathrm{R}^{1}, \mathrm{R}^{2}=\text { cyclic/acyclic } \mathrm{N} \text {-tosylaziridines } \\
& \mathrm{R}^{3}=\mathrm{H}, \mathrm{CO}_{2} \mathrm{Me}, \mathrm{Me}, \mathrm{Cl}, \mathrm{Ph}, \mathrm{t} \text { - Bu } \\
& \begin{array}{l}
\mathrm{CO}(1.38 \mathrm{MPa}), 80^{\circ} \mathrm{C}, 24 \mathrm{~h} \\
\mathrm{~K}_{2} \mathrm{CO}_{3}, \mathrm{TEBA}(10 \mathrm{~mol} \%)
\end{array}
\end{aligned}
$$

2014 年, Ghorai 课题组 ${ }^{[60]}$ 报道了一种高效合成四氢 化苯并氧氮草、四氢化苯并硫氮草及咪唑衍生物的方法 (Scheme 16). 首先路易斯酸催化 $N$-活化的氮杂环丙烷 与 2-溴代苄基醇或硫醇发生 $\mathrm{S}_{\mathrm{N}} 2$ 开环反应，接着在 $\mathrm{Cu}$ 催化下进行分子内芳胺化得到相应的产物. 而氮杂与 2溴代苄基胺的反应是在开环之后，于 $\mathrm{Cu}$ 催化下发生交 叉脱氢环化反应和乌尔曼 $\mathrm{C}-\mathrm{N}$ 键形成反应来得到并环

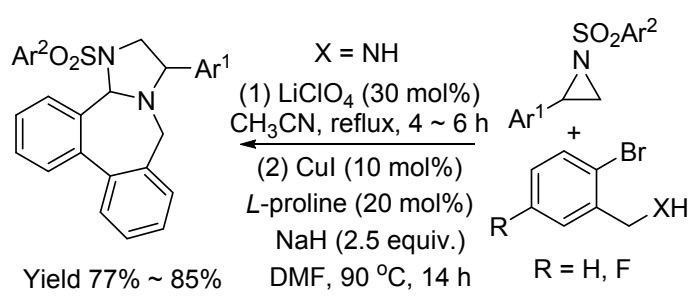

$$
\mathrm{X}=\mathrm{O}, \mathrm{S}
$$

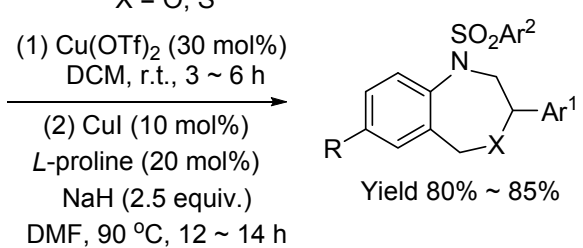

图式 16 氮杂环丙烷与 2-溴代苄基醇或硫醇的环加成反应 Scheme 16 [3+4] cycloadditions of aziridines with 2-bromobenzyl alcohol and mercaptan 
产物. 对不同的氮杂与 2-溴代芐基醇、芐硫醇以及芐胺 的扩展反应，都得到了良好的收率.

\section{4 氮杂环丙烷 $[3+2+2]$ 环加成反应}

2014 年, 李金恒课题组 ${ }^{[61]}$ 报道了用六氟锑酸作催 化剂催化氮杂环丙烷与炔烃的 $[3+2+2]$ 环加成反应 (Eq. 46). 该反应以 $N$-对甲苯磺酰基苯乙烷氮杂环丙烷 与苯乙炔作标准底物, 六氟锑酸作催化剂, 在氩气保护 下以二氯甲烷作溶剂、 $40{ }^{\circ} \mathrm{C}$ 条件下反应得到七元环产 物. 对 27 种底物的扩展表明反应都取得中等以上的收 率. 当两种不同的端基炔烃与氮杂环丙烷反应均能取得 同样的效果. 反应得到的 2,3-二氢-1- $H$-听庚因衍生物是 众多天然产物、药物以及多肽的骨架结构, 有着很重要 的合成价值.

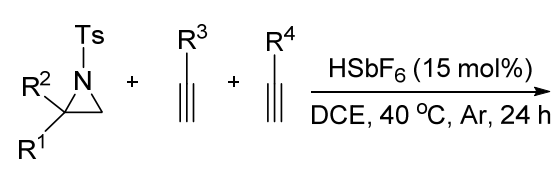

$R^{1}: A r, R^{2}: H, M e$

$R^{3}=R^{4}$ or $R^{3} \neq R^{4}: A r$, alkyl

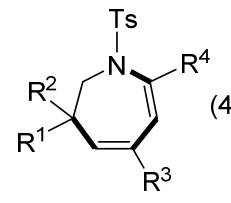

Yield $62 \% \sim 78 \%$

\section{5 氮杂环丙烷 $[5+2]$ 环加成反应}

2012 年, Saito 课题组 ${ }^{[62]}$ 在无催化剂温和的条件下 利用乙烯基氮杂环丙烷与磺酰异氧酸酯发生 $[5+2]$ 环加 成反应制得高收率的七元环尿素酶(Eq. 47). 研究发现 异氧酸酯与溶剂的选择对反应的进展是至关重要的, 对 于供电子的异氧酸酯, 反应收率较低同时产物不易分 离, 而对于磺酰基取代的异氧酸酯与带有不同取代基的 氮杂反应都可取得较高的收率, 最高可达 $98 \%$, 反式氮 杂发生反应取得相应的七元环产物收率高且反应速度 快, 顺式氮杂则相对较慢, 且产物收率低.<smiles>[R]N=C=O</smiles>

$\mathrm{R}^{1}=\mathrm{H}, \mathrm{Me}, \mathrm{Ph}$, OTBS $\mathrm{R}^{2}=n-\mathrm{Bu}, \mathrm{Cy}, \mathrm{DMB}$ $\mathrm{R}^{3}=\mathrm{Ts}, \mathrm{Ms}$

2015 年, 张俊良课题组 ${ }^{[63]}$ 在室温下通过铑催化剂 $\left[\mathrm{Rh}(\mathrm{NBD})_{2}\right] \mathrm{BF}_{4}$ 高效实现了烯基氮杂环丙烷-炔类底物 的分子内杂 $[5+2]$ 环加成反应(Eq. 48), 该反应具有很好 的对映选择性和优秀的收率; 在温和条件下为含氮杂七 元环的多环并环类化合物的合成提供了一个原子经济 性和高对映选择性的绿色合成路线. 同时利用 “手性转 移” 策略, 实现了原料手性在产物中的保持, 从而实现 了对这类手性化合物的高效不对称合成.

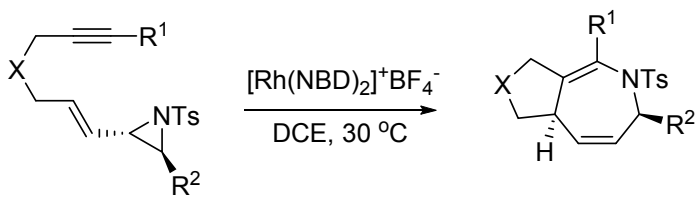

$\mathrm{R}^{1}=\mathrm{H}$, alkyl, aryl, heteroaryl

$\mathrm{R}^{2}=\mathrm{H}, \mathrm{Me}, i-\mathrm{Pr}, n-\mathrm{Pr}$

Yield up to $95 \%$

$\mathrm{X}=\mathrm{NTs}, \mathrm{O}, \mathrm{C}\left(\mathrm{CO}_{2} \mathrm{Me}\right)_{2}$

\section{6 氮杂环丙烷 $[6+3]$ 环加成反应}

2011 年, Hayashi 课题组 ${ }^{[64]}$ 报道了在钯催化剂催化 作用下 $\gamma$-methylidene- $\delta$-valerolactone 与氮杂环丙烷发生 $[6+3]$ 环加成得到 1,4-oxazonan-9-ones 的反应(Scheme 17)，该反应相对于现有制备九元环内酯氮杂的方法来 说，更简单高效. 在最优的反应条件下，对不同的 $\gamma$ methylidene- $\delta$-valerolactones 以及氮杂进行扩展，反应都 取得了中等到优秀的反应收率.

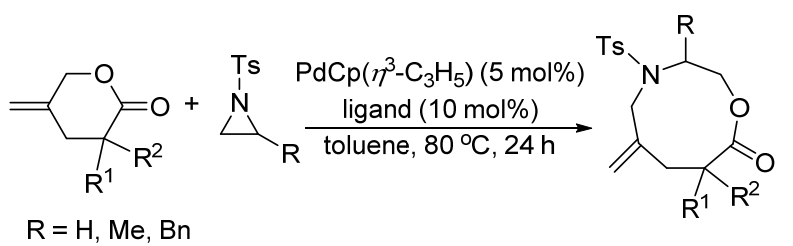

$$
\mathrm{R}^{1}=\mathrm{Me}, \mathrm{Ph}, \mathrm{Bn}, 4-\mathrm{ClC}_{6} \mathrm{H}_{4}, \mathrm{~S}\left(\mathrm{CH}_{2}\right)_{3} \mathrm{~S}
$$
Yield 53\% 87\%

$\mathrm{R}^{2}=\mathrm{H}, \mathrm{Me}, \mathrm{CO}_{2} \mathrm{Me}, \mathrm{Ph}, 4-\mathrm{ClC}_{6} \mathrm{H}_{4}$<smiles></smiles>

图式 17 钯催化氮杂环丙烷与 $\gamma$-methylidene- $\delta$-valerolactone 的环加成反应

Scheme 17 Palladium-catalyzed formal [6+3] cycloadditions of aziridines with $\gamma$-methylidene- $\delta$-valerolactone

\section{6 结论与展望}

综上所述, 经过化学工作者的不断努力, 大量的咪 唑烷、噁唑烷、吡咯烷、噻唑、喹啉、吗啉等多元氮杂 环的合成方法得到了改进或创新，但在该研究领域还存 在着许多难题有待进一步发展，继续寻找更廉价高效的 催化剂、构建温和的反应条件、控制副产物的产生以及 获得高纯度的光学活性手性化合物等成为新的研究热 点.

\section{References}

[1] Brichacek, M.; Lee, D. E.; Njardarson, J. T. Org. Lett. 2008, 10, 5023.

[2] Li, L.; Wu, X.; Zhang, J. Chem. Commun. 2011, 47, 5049.

[3] Lowe, M. A.; Ostovar, M.; Ferrini, S.; Chen, C. C.; Lawrence, P. G.; Fontana, F.; Calabrese, A. A.; Aggarwal, V. K. Angew. Chem., Int. 


\section{Ed. 2011, 50, 6370.}

[4] Griffin, K.; Montagne, C.; Hoang, C. T.; Clarkson, G. J.; Shipman, M. Org. Biomol. Chem. 2012, 10, 1032.

[5] Arena, G.; Chen, C. C.; Leonori, D.; Aggarwal, V. K. Org. Lett. 2013, 15, 4250.

[6] Takahashi, H.; Yasui, S.; Tsunoi, S.; Shibata, I. Org. Lett. 2014, 16, 1192.

[7] Martinand-Lurin, E.; Gruber, R.; Retailleau, P.; Fleurat-Lessard, P.; Dauban, P. J. Org. Chem. 2015, 80, 1414.

[8] Xu, C. F.; Zheng, B. H.; Suo, J. J.; Ding, C. H.; Hou, X. L. Angew. Chem., Int. Ed. 2015, 54, 1604.

[9] Wang, L.; Yang, D.; Han, F.; Li, D.; Zhao, D.; Wang, R. Org. Lett. 2015, 17, 176

[10] Huang, Y.; Zheng, C.; Pan, L.; Jin, Q.; Zhao, G. J. Org. Chem. 2015, 80, 10710 .

[11] Zhu, W.; Cai, G.; Ma, D. Org. Lett. 2005, 7, 5545.

[12] Wender, P. A.; Strand, D. J. Am. Chem. Soc. 2009, 131, 7528

[13] Fan, J.; Gao, L.; Wang, Z. Chem. Commun. 2009, 5021.

[14] Zhao, X.; Zhang, E.; Tu, Y. Q.; Zhang, Y. Q.; Yuan, D. Y.; Cao, K.; Fan, C. A.; Zhang, F. M. Org. Lett. 2009, 11, 4002.

[15] Khlebnikov, A. F.; Novikov, M. S.; Petrovskii, P. P.; Konev, A. S.; Yufit, D. S.; Selivanov, S. I.; Frauendorf, H. J. Org. Chem. 2010, 75,5211 .

[16] Li, L.; Zhang, J. Org. Lett. 2011, 13, 5840.

[17] Kim, M. S.; Kim, Y. W.; Hahm, H. S.; Jang, J. W.; Lee, W. K.; Ha, H. J. Chem. Commun. 2005, 3062.

[18] Jiang, Z.; Wang, J.; Lu, P.; Wang, Y. Tetrahedron 2011, 67, 9609.

[19] Wu, X.; Zhang, J. Synthesis 2012, 44, 2147.

[20] Yadav, V. K.; Sriramurthy, V. J. Am. Chem. Soc. 2005, 127, 16366.

[21] Ghorai, M. K.; Ghosh, K.; Das, K. Tetrahedron Lett. 2006, 47, 5399.

[22] Wu, J.; Sun, X.; Xia, H. G. Tetrahedron Lett. 2006, 47, 1509.

[23] Yadav, J. S.; Subba Reddy, B. V.; Pandurangam, T.; Subba Reddy, U. V. Chem. Lett. 2008, 37, 824.

[24] Li, X.; Yang, X.; Chang, H.; Li, Y.; Ni, B.; Wei, W. Eur. J. Org. Chem. 2011, 3122.

[25] Yoshiki, M.; Ishibashi, R.; Yamada, Y.; Hanamoto, T. Org. Lett. 2014, 16, 5509 .

[26] Ghorai, M. K.; Ghosh, K. Tetrahedron Lett. 2007, 48, 3191.

[27] Kang, B.; Miller, A. W.; Goyal, S.; Nguyen, S. T. Chem. Commun. 2009, 3928.

[28] Maeda, R.; Ishibashi, R.; Kamaishi, R.; Hirotaki, K.; Furuno, H.; Hanamoto, T. Org. Lett. 2011, 13, 6240.

[29] Wu, X.; Li, L.; Zhang, J. Chem. Commun. 2011, 47, 7824.

[30] Yang, H. T.; Xing, M. L.; Zhu, Y. F.; Sun, X. Q.; Cheng, J.; Miao, C. B.; Li, F. B. J. Org. Chem. 2014, 79, 1487.

[31] Du, Y.; Wu, Y.; Liu, A. H.; He, L. N. J. Org. Chem. 2008, 73, 4709.

[32] Wu, Y.; He, L. N.; Du, Y.; Wang, J. Q.; Miao, C. X.; Li, W. Tetrahedron 2009, 65, 6204.
[33] Zhao, Y. N.; Yang, Z. Z.; Luo, S. H.; He, L. N. Catal. Today 2013, $200,2$.

[34] Dou, X. Y.; He, L. N.; Yang, Z. Z.; Wang, J. L. Synlett 2010, 2159.

[35] Phung, C.; Ulrich, R. M.; Ibrahim, M.; Tighe, N. T. G.; Lieberman, D. L.; Pinhas, A. R. Green Chem. 2011, 13, 3224.

[36] Wu, Y.; Liu, G. Tetrahedron Lett. 2011, 52, 6450.

[37] Fontana, F.; Chen, C. C.; Aggarwal, V. K. Org. Lett. 2011, 13, 3454.

[38] Seayad, J.; Seayad, A. M.; Ng, J. K. P.; Chai, C. L. L. ChemCatChem 2012, 4, 774.

[39] Ueno, A.; Kayaki, Y.; Ikariya, T. Green Chem. 2013, 15, 425.

[40] Nale, D. B.; Rana, S.; Parida, K.; Bhanage, B. M. Appl. Catal. A: Gen. 2014, 469, 340.

[41] Chen, W.; Zhong, L.; Peng, X.; Sun, R.; Lu, F. ACS Sustainable Chem. Eng. 2015, 3, 147.

[42] Wu, J. Y.; Luo, Z. B; Dai, L. X.; Hou, X. L. J. Org. Chem. 2008, 73, 9137.

[43] Chen, N.; Jia, W.; Xu, J. Eur. J. Org. Chem. 2009, 5841.

[44] Sengoden, M.; Punniyamurthy, T. Angew. Chem., Int. Ed. 2013, 52, 572.

[45] Cui, S. L.; Wang, J.; Wang, Y. G. Org. Lett. 2008, 10, 13.

[46] Ghorai, M. K.; Tiwari, D. P. J. Org. Chem. 2010, 75, 6173.

[47] Ghorai, M. K.; Tiwari, D. P. J. Org. Chem. 2013, 78, 2617.

[48] Munegumi, T.; Azumaya, I.; Kato, T.; Masu, H.; Saito, S. Org. Lett. 2006, 8,379 .

[49] Sengoden, M.; Vijay, M.; Balakumar, E.; Punniyamurthy, T. RSC Adv. 2014, 4, 54149.

[50] Craig, R. A.; O'Connor, N. R.; Goldberg, A. F. G.; Stoltz, B. M. Chem. Eur. J. 2014, 20, 4806.

[51] Goodenough, K. M.; Raubo, P.; Harrity, J. P. A. Org. Lett. 2005, 7, 2993.

[52] Wang, L.; Liu, Q. B.; Wang, D. S.; Li, X.; Han, X. W.; Xiao, W. J.; Zhou, Y. G. Org. Lett. 2009, 11, 1119.

[53] Bera, M.; Roy, S. J. Org. Chem. 2009, 74, 8814.

[54] Ghorai, M. K.; Shukla, D.; Das, K. J. Org. Chem. 2009, 74, 7013.

[55] Guo, H.; Xu, Q.; Kwon, O. J. Am. Chem. Soc. 2009, 131, 6318.

[56] Ghorai, M. K.; Nanaji, Y.; Yadav, A. K. Org. Lett. 2011, 13, 4256.

[57] Wang, S.; Chai, Z.; Zhou, S.; Wang, S.; Zhu, X.; We, Y. Org. Lett. 2013, 15, 2628.

[58] Wang, L.; Yang, D.; Li, D.; Wang, R. Org. Lett. 2015, 17, 3004.

[59] Chouhan, G.; Alper, H. Org. Lett. 2010, 12, 192.

[60] Ghorai, M. K.; Sahoo, A. K.; Bhattacharyya, A. J. Org. Chem. 2014, 79, 6468.

[61] Zhou, M. B.; Song, R. J.; Li, J. H. Angew. Chem., Int. Ed. 2014, 53, 4196.

[62] Kanno, E.; Yamanoi, K.; Koya, S.; Azumaya, I.; Masu, H.; Yamasaki, R.; Saito, S. J. Org. Chem. 2012, 77, 2142.

[63] Feng, J. J.; Lin, T. Y.; Wu, H. H.; Zhang, J. J. Am. Chem. Soc. 2015, 137, 3787.

[64] Shintani, R.; Ikehata, K.; Hayashi, T. J. Org. Chem. 2011, 76, 4776.

$(\mathrm{Lu}, \mathrm{Y}$. 